\title{
EL REGRESO DE LOS ENCLAVES A HONDURAS EN EL SIGLO XXI: LAS ZONAS DE EMPLEO Y DESARROLLO ECONÓMICO (ZEDE), LA VERSIÓN DE LAS CIUDADES CHÁRTER RECHAZADA POR SU CREADOR PAUL ROMER (2010-2019)
}

\author{
THE RETURN OF THE ENCLAVES TO HONDURAS IN THE XXI CENTURY: \\ THE ZONES OF EMPLOYMENT AND ECONOMIC DEVELOPMENT (ZEDE), \\ THE VERSION OF THE CHARTER CITIES REJECTED \\ BY ITS CREATOR PAUL ROMER (2010-2019)
}

José Luis Palma-Herrera

Recibido: 11/02/2019 - Aceptado: 05/08/2019

\begin{abstract}
Resumen
En su génesis, los objetivos de las ZEDE, basados en la teoría de las Ciudades Chárter de Paul Romer, eran generar oportunidades laborales, desarrollo económico y ofrecer seguridad a la población de Honduras, con el fin de reducir la inmigración ilegal a los Estados Unidos de América. Sin embargo, con el surgimiento de las Caravanas Migrantes y después de una década de incertidumbre política, esta propuesta de desarrollo ha demostrado ser una más de las falacias políticas vernáculas de Honduras, caracterizada por su falta de transparencia, carencia de indicadores de desarrollo económico, desplazamiento de la autonomía municipal e indiferencia por la reducción de la pobreza nacional. El presente estudio muestra cómo las ZEDE forman parte de la lista histórica de enclaves fallidos hondureños.
\end{abstract}

Palabras clave: enclave, ciudad chárter, concesión, territorio, corrupción.

\begin{abstract}
In its genesis, the objectives of the ZEDE, based on the theory of the Charter Cities of Paul Romer, were to generate job opportunities, economic development and offer security to the population of Honduras to reduce illegal immigration to the United States of America. However, with the emergence of the Migrant Caravans and after a decade of political uncertainty, this development proposal has proven to be one of the vernacular political fallacies of Honduras, characterized by its lack of transparency, lack of indicators of economic development, displacement of municipal autonomy and indifference to the reduction of national poverty. The present study shows how the ZEDE are already part of the historical list of failed Honduran enclaves.
\end{abstract}

Keywords: enclave, charter cities, concession, territory, corruption. 


\section{Introducción}

Al finalizar el discurso de su segunda toma de posesión presidencial, el abogado Juan Orlando Hernández cometió lo que para muchos fue un "lapsus línguae" al despedir su disertación con la frase "Un abrazo, para todas y todos, los que están aquí y los que están allá, en Honduras". Sin embargo, dicha frase puede ser prueba de la visión de desarrollo de la persona que tiene en sus manos el destino de cada kilómetro cuadrado del territorio de un país que aún es catalogado como una "República Bananera", a pesar de que desde 1975 la política de los enclaves bananeros fue abolida mediante la cancelación de las contratas o concesiones respectivas. La expresión "los que están aquí y los que están allá" demuestra la realidad que actualmente caracteriza a Honduras como un país dividido en dos facciones: los primeros que apoyan las políticas centralizadoras, totalitarias y concesionarias; y los segundos que defienden la transparencia, descentralización gubernamental, autonomía municipal, protección ambiental y soberanía territorial nacional.

La división ideológica de un país en dos bandos puede ser materializada y fragmentada en muchas más partes, especialmente en "fragmentos territoriales independientes". Lo anterior se puede lograr mediante la creación y el uso de figuras legales que concesionen una amplia gama de derechos y beneficios a quien esté dispuesto a invertir en estas fragmentaciones territoriales. La figura legal usada en Honduras para otorgar estos fragmentos territoriales, históricamente, es la concesión. Desde que la "administración nacionalista"1 ha guiado la política de desarrollo del país, la figura de la concesión territorial ha tomado tanta fuerza como en la época en que las concesiones mineras y bananeras parecían ser el bastión de desarrollo económico de Honduras. Prueba de esto es la política agresiva que esta gestión ha realizado en cuanto a concesionamiento de servicios públicos, infraestructura, recursos naturales y producción energética.

La figura más conocida y controversial de esta política de "fragmentación territorial" son quizás las Zonas de Empleo y Desarrollo Económico (ZEDE), mejor conocidas como "ciudades modelo", las cuales representan para muchas personas, dentro y fuera de Honduras, el renacer de los enclaves en el país. Por ello, sorprende que en pleno siglo XXI un gobierno genere una figura legal que permita darle un trozo de país a inversionistas internacionales, sin estudios que respalden si el impacto será realmente beneficioso para la población en general o si el "trueque" de desarrollo económico a cambio de la soberanía nacional no es una falacia política más de las tantas que forman parte de una lista de antecedentes nacionales que muestran que esta política concesionaria no es nueva, ni tampoco beneficiosa para el país.

El discurso de la toma de posesión del Abogado Hernández en el 2018, en su fragmento "los que están aquí y los que están allá, en Honduras", ha dejado la impresión de que existen dos Honduras, la Honduras de aquí y la Honduras de allá. 
Dicha impresión ya había sido identificada años atrás por el New York Times en el artículo "Who Wants to Buy Honduras?" (Davidson), donde se observa una descarada política de enclave en toda esta iniciativa concesionaria de territorio, la cual pareciera que busca separar al país en una "Honduras buena de aquí", con la "Honduras mala de allá" (Figura 1).

Figura 1

LA NUEVA HONDURAS, ESTABLECIDA EN 2010

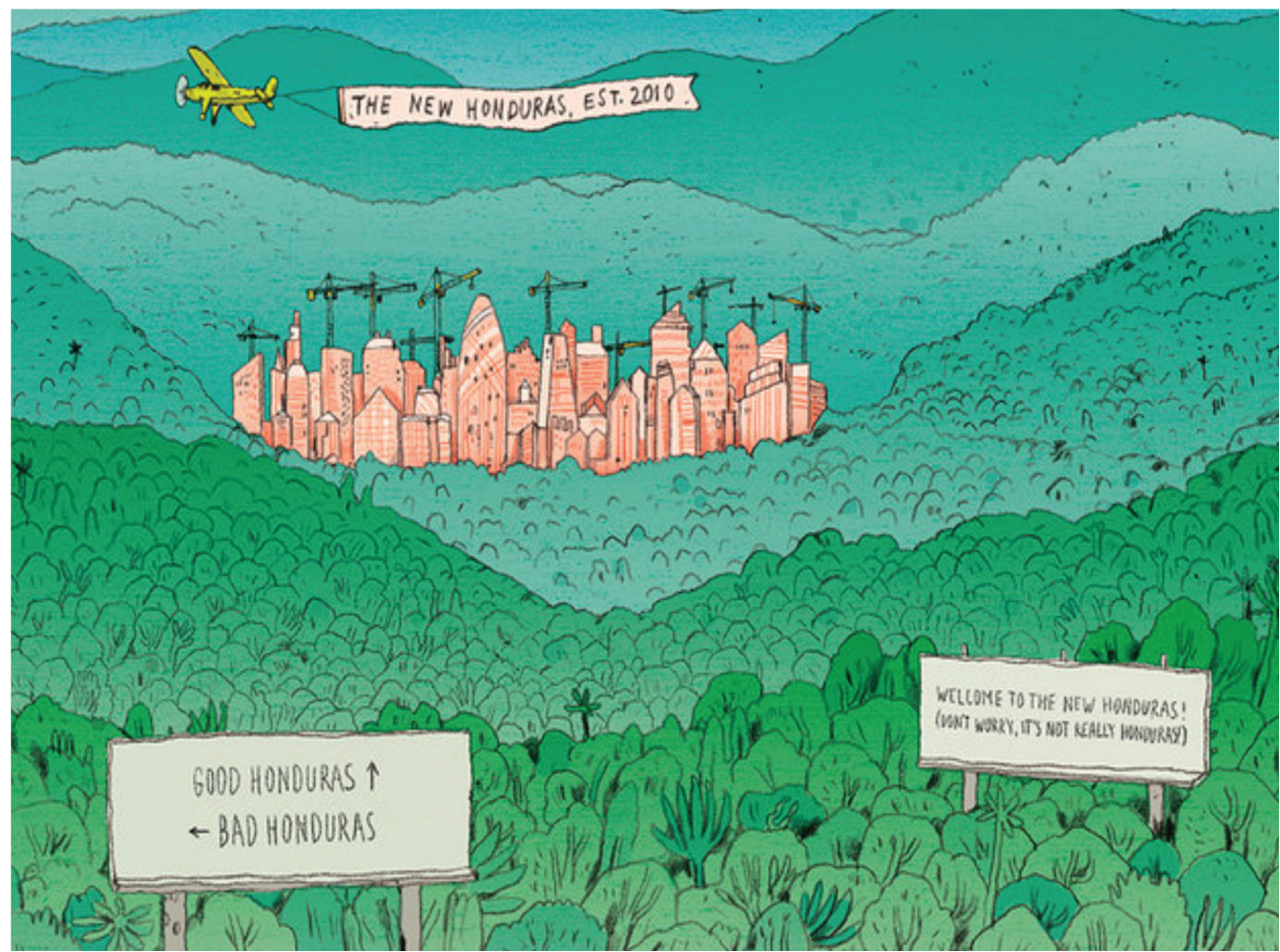

Fuente: Davidson.

\section{La histórica dificultad de investigar académicamente en Honduras}

Una de las herencias del sistema de gobierno colonial español para Centroamérica, que hasta hoy sobrevive en Honduras, es la estrategia política por parte de las autoridades de evitar la generación o acceso a información del país referente a sus problemáticas, historia, población, producción, democracia, recursos naturales y gobernanza, entre otros. Tal y como lo vivió el propio investigador Squier ${ }^{2}$ cuando realizó estudios en Honduras a mediados del siglo XIX para analizar la factibilidad de 
instalar un ferrocarril interoceánico y cuya sorpresa de no poder acceder a información para sus investigaciones le hizo escribir en una de sus obras lo siguiente:

Aun personas que se supone están mejor instruidas sobre las peculiaridades del país, no son capaces de dar un informe circunstanciado y exacto acerca de ellas, y el investigador tiene que sujetarse a su propio trabajo, tan penoso y difícil, que no deja de desalentar. En vano se buscan libros impresos o documentos que lo ayuden. De los pocos que puede recoger no hay una sola colección completa, y en vano se buscan también datos en los archivos públicos, donde un total abandono y falta de orden hace imposible adquirir ninguno (Squier 32).

Casi dos siglos después de los estudios de Squier las cosas no han cambiado mucho en estas honduras, ya que es gracias a la cooperación internacional y los fondos otorgados por esta que existe actualmente información nacional crucial para cualquier país del mundo, por ejemplo, censos poblacionales y de vivienda, cartografía básica, geoinformación de pérdida de cobertura de bosques, catastros multipropósitos de tierras, datos sobre recursos naturales y biodiversidad, entre otros. Sin la buena voluntad de estas entidades y gobiernos amigos, mucha de la información utilizada hoy en día para la toma de decisiones relacionadas con el desarrollo sostenible e inclusivo del país no sería posible, seguiríamos viviendo en el oscurantismo, mantenido por nuestra autoridades actuales y heredado por aquellos colonizadores que explotaron lo que se conoció en su momento como el país más rico de Centroamérica. ${ }^{3}$

Por ello, en pleno siglo XXI, cualquier persona que busque datos relacionados con las ZEDE encontrará poca o nula información oficial, no más que un par de decretos que son superficiales a nivel funcional y geográfico de dichas concesiones. Después de esto, existen varios reportajes periodísticos que muestran que las autoridades responsables de estas zonas repiten mecánica y metódicamente los mismos asuntos sin lograr profundizar en el tema o en los supuestos inversionistas interesados.

Después de casi doscientos años desde el estudio de Squier, continúa vigente el celoso y exclusivo sistema de dominar el país haciendo desfavorable cualquier clase de investigación aplicada sobre como el Gobierno administra el territorio nacional. Por lo cual todo aquel investigador que busca conocer, analizar y proponer posibles soluciones a los problemas de desarrollo, transparencia e inclusión que sufre esta nación atormentada por la política vernácula que la caracteriza, luchará contra un mecanismo de dominio arraigado desde hace varios siglos.

\section{Antecedentes de los enclaves en Honduras}

Popularmente, incluso académicamente, se cree erróneamente que las compañías bananeras estadounidenses (junto con los gobernantes nacionales de la época) fundaron los primeros enclaves ${ }^{4}$ en Honduras, cuando en realidad esta figura existió previo a estos eventos en los albores de la República, de hecho, hay estudios donde se 
estima que desde la época precolombina ya existía un enclave, ya que se ha teorizado que la ciudad maya de Copán fue un enclave de este Imperio.

De acuerdo con patrones resultantes de recientes análisis isotópicos en tumbas mayas de Copán, se ha comprobado que existe un interesante número de élites enterradas en esta ciudad que no fueron locales. Dicho estudio analizó los restos de dos gobernantes dinásticos en el sitio donde se descubrió que estos nacieron, a una gran distancia de Copán; vinieron de las tierras bajas mayas. Algunos de sus sirvientes y otros individuos enterrados cerca de ellos tampoco eran originarios de Copán (Price et al.). Los resultados refuerzan la teoría explicada por el profesor William Fash años atrás, quien indica que el predominio de los gobernantes nacidos en el extranjero ha llevado a la idea de que Copán dinástico fue fundado como un "enclave de élite" lejos de los centros mayas (Citado por Price et al. 45). Esta independencia se puede apreciar geográficamente en el mapa de línea base de isótopos de estroncio disponibles en el área maya, el cual se muestra en la Figura 2.

Figura 2

MAPA DE LÍNEA BASE DE ISÓTOPOS DE ESTRONCIO DISPONIBLES EN EL ÁREA MAYA

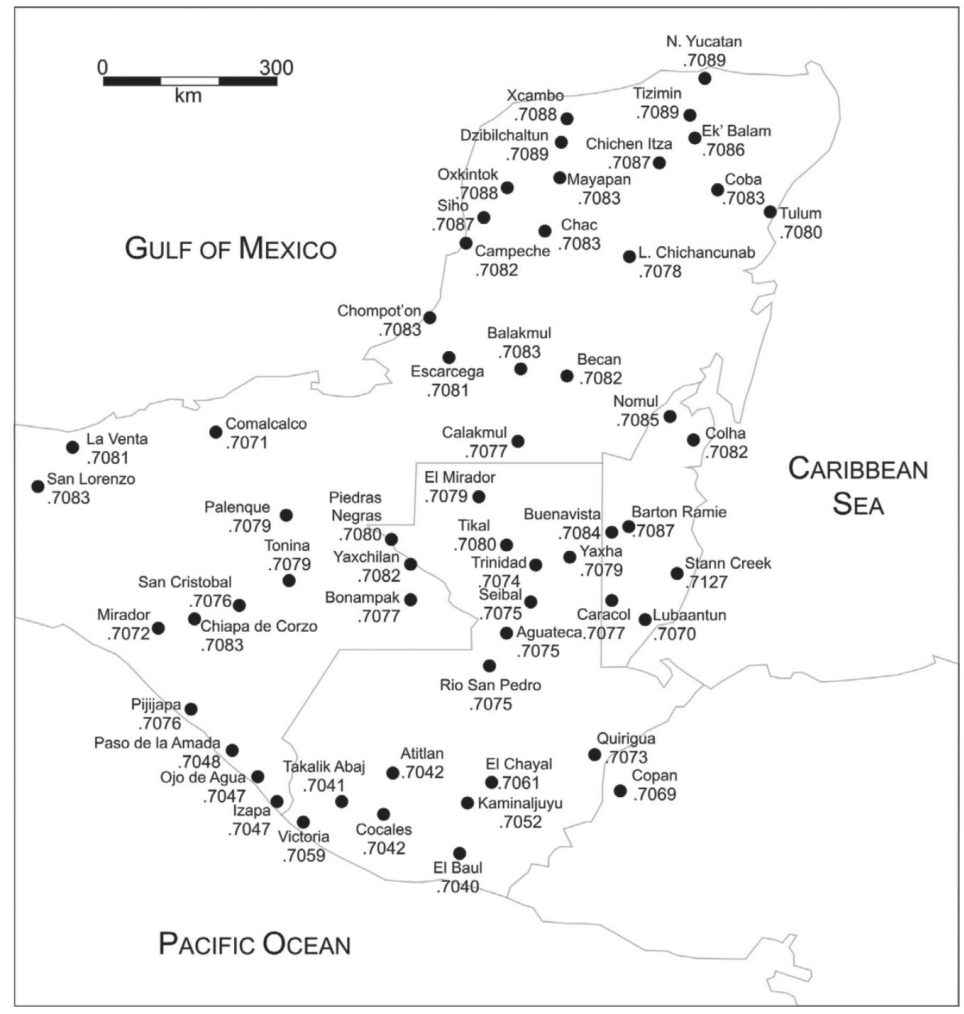

Fuente: Price et al. 39 . 
Al finalizar la época de la Colonia en Honduras y comenzar la época republicana, la esperanza de sus pobladores yacía en que la autonomía de un gobierno democrático elegido por el pueblo, y para el pueblo, aseguraría el bienestar y desarrollo de la nueva nación y sus pobladores, para lo cual, el respeto y defensa de su territorio recién recuperado era vital. No obstante, el tiempo nos demostraría que este anhelo no sería tan fácil de cumplir, ya que un par de décadas después de alcanzar la independencia, la clase política gobernante de la joven República comenzó a ver en el concesionamiento de su territorio una forma rápida y austera para alcanzar el desarrollo del país, puesto que, ante la carencia de recursos financieros propios y la falta de capacidad para generarlos, la abundancia del recurso tierra era la única opción. Esta salida fácil es lo que el Imperio español hizo siglos atrás, cuando, ante su incapacidad de pagar a los "colonizadores" de su imperio con recursos propios, les pago con caballerías y peonias de tierra del Nuevo Mundo, lo cual era muy conveniente, ya que no costaba absolutamente nada otorgar tierras que no eran propias. Dicha estrategia política demagógica perdura desde el nacimiento de la República hasta el momento actual, lo cual demuestra cómo la herencia del Imperio español está arraigada en el pensamiento político de los gobernantes vernáculos desde hace más de medio milenio.

\section{El primer enclave en la República de Honduras}

De acuerdo con Squier, para 1855 entre los mejores tres puertos del Pacífico en Centroamérica se encontraba el Puerto Libre de Amapala; y como explica Wells, dicho puerto inició operaciones con el concesionamiento en 1846 de varias caballerías de tierra al comerciante italiano Don Carlos Dárdano Dota y con el respaldo del decreto de 1847 donde se le nombra "Puerto franco de Amapala en la isla del Tigre". En dicho decreto se establece que no se pagarían derechos marítimos de ninguna especie durante diez años, gracias a este puerto nació el comercio internacional en el Pacífico de Honduras en el siglo XIX.

Para el segundo semestre de 1882, el puerto de Amapala recaudaba más de la mitad (58 por ciento) de los tributos del comercio internacional de Honduras por concepto de importación y exportación en los puertos nacionales (Molina-Chocano). Para ese entonces, parecería que el puerto de Amapala era un ejemplo de desarrollo gracias a la figura de la concesión; sin embargo, como lo explica Durón, la verdad sobre este puerto es otra. El 20 de enero de 1849 tomó posesión Don Dárdano Dota, como superintendente de la isla del Tigre, y demás islas adyacentes, en nombre de la Reina, ${ }^{5} \mathrm{y}$ desde luego con el respaldo del poderío del Imperio de Gran Bretaña, todo esto a pesar del rechazo oficial tanto del gobierno hondureño como de los vecinos gobiernos de El Salvador y Nicaragua. El supuesto justificante de esta obra, en contra de los principios del Derecho Internacional (como lo tildaba el gobierno hondureño entonces), explicaba el Consulado británico, radicaba en que la toma de posesión de la isla de Amapala 
(y del puerto de Trujillo también) era una forma de compensación por una deuda entre el gobierno hondureño y la corona inglesa (Durón). Debido a todo esto, el territorio de la Isla del Tigre y resto del Golfo de Fonseca estuvo en manos del Imperio británico a mediados del siglo XIX. Con todo lo mencionado anteriormente, se puede confirmar que Amapala se convirtió en el primer enclave en territorio hondureño iniciado a través de la figura de la concesión de territorio.

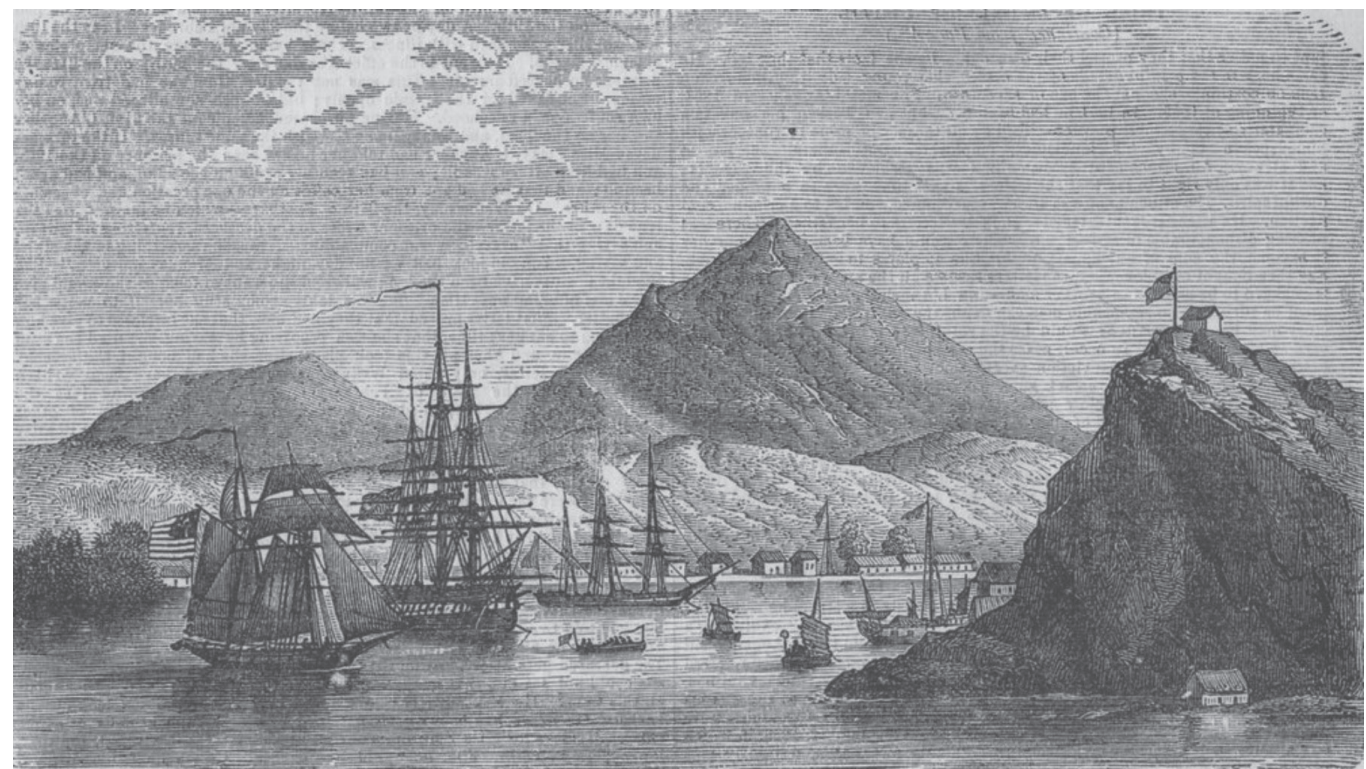

Fuente: Illustrated London News, 1857.

Cabe notar que el Imperio británico trataba de darle importancia a su enclave a través de medios de comunicación popular en su época, como el Illustrated London News; sin embargo, al comparar cómo mostraban los británicos su enclave (Figura 3) y cómo lo mostraban otros visitantes extranjeros (Figura 4), se puede apreciar que se trataba de presentar ante los ojos del mundo algo que no era totalmente real.

La Isla del Tigre y el Golfo de Fonseca, solo fueron el principio de una conquista moderna, ya que en agosto de 1850 la armada inglesa se apodera de las islas caribeñas hondureñas y son declaradas propiedad de la Corona con el nombre de "Colonia Británica de las Islas de la Bahía" y establece autoridades inglesas en las mismas. Posteriormente, en 1852 el gobierno británico declara que las Islas de la Bahía (Bay Islands) son dependencia del territorio de "Honduras Británica", conocido actualmente como Belice (Selser). 


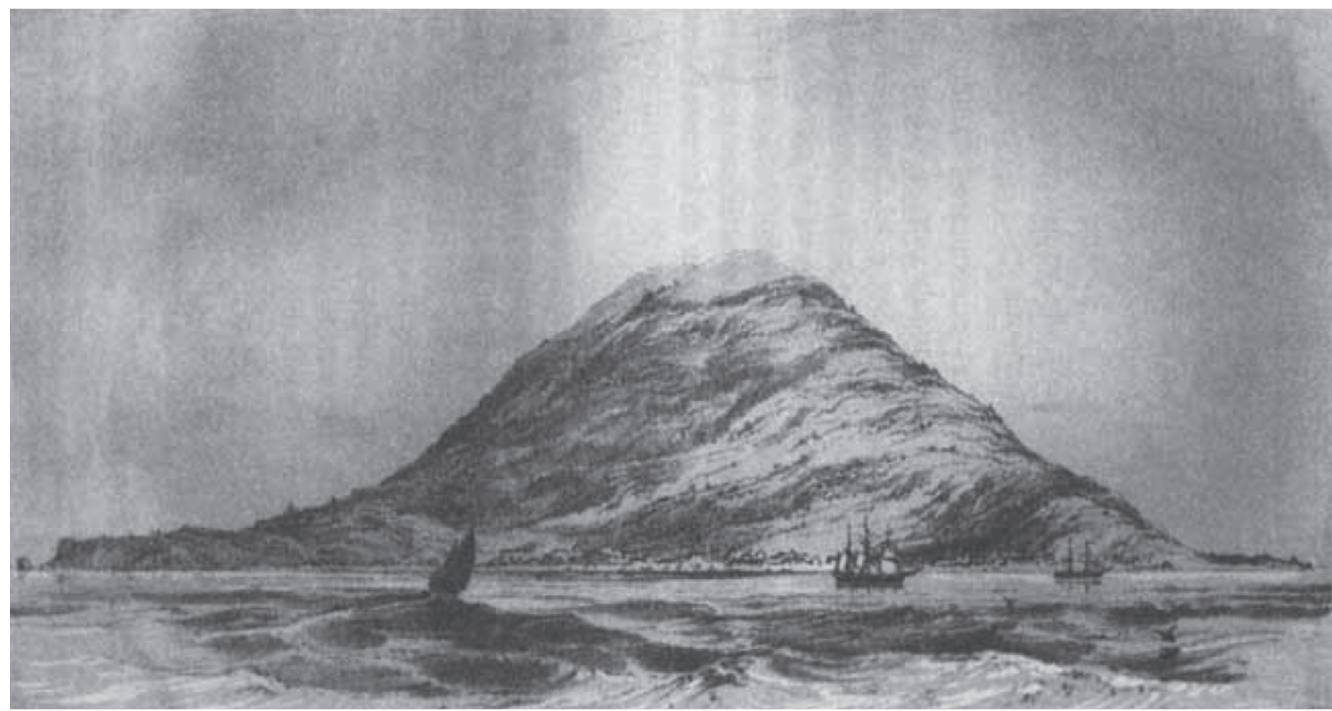

Fuente: Squier 52.

\section{Los enclaves mineros y bananeros en Honduras}

Murga Frassinetti, en su libro Enclave y Sociedad en Honduras, indica que en las administraciones de Marco Aurelio Soto y Luis Bográn (1876-1891) se inició la transformación de una economía hondureña aislada ${ }^{6}$ y de subsistencia a una economía subordinada al mercado capitalista mundial, esto como una solución al problema nacional de estancamiento y crisis crónica que la joven República sufrió en su primer medio siglo de existencia. Esta subordinación se concretó con el establecimiento de la figura de la concesión del territorio al capital extranjero en el marco jurídico de Honduras, tanto en su constitución como en sus leyes conexas. ${ }^{7}$ La prueba de esto se puede encontrar en la Constitución de Honduras de $1880,{ }^{8}$ donde se establece la figura de la concesión como un elemento indispensable para "garantizar el progreso", a la vez, se da apertura total a la incursión del capital extranjero en esta iniciativa, tal y como se indica en el artículo 25 de esta:

El Estado proveerá todo lo conducente al bienestar y adelanto del país, fomentando el progreso de la agricultura, de la industria y del comercio... de la importación de capitales extranjeros... por medio de leyes protectoras de estos fines, y de concesiones temporales de privilegios y recompensas de estímulo (Congreso Nacional de Honduras). 
Con esta apertura al concesionamiento del territorio, se originaron los enclaves mineros y bananeros, respectivamente.

El segundo enclave originado en Honduras mediante la concesión de territorio es el llamado "enclave minero" (Murga Frassinetti; Molina-Chocano). Dicho enclave comienza operativamente con el inicio de actividades de la Rosario Mining Company, a quien se le concesionó la explotación a 20 años de la mina de El Rosario en San Juancito.

Posteriormente, con la divulgación de mapas de minas y sus prospectos, las concesiones mineras a inversionistas extranjeros aumentaron; la gran mayoría de estos eran de origen estadounidense, con lo cual se conformó el "Central American Syndicate". ${ }^{9}$ En este periodo las concesiones incluían enormes privilegios aduaneros, exenciones de tributos y acceso total a los recursos naturales necesarios para la explotación minera, tales como "el agua". Entre 1888 y 1889 la minería representaba el 55 por ciento de las exportaciones nacionales, en dicha época se encontraban registradas cerca de 300 minas de oro, plata, plomo y cobre (Molina-Chocano).

Nuevamente, parecía que la concesión del territorio resultaba en un éxito para la economía nacional, pero al analizar cuánto de lo exportado se transforma en desarrollo económico y social para el país, los resultados muestran otra cosa. A partir de la concesión a la Rosario, y gracias a las condiciones favorables generados por el Estado hacia esta (y todas las otras compañías que vendrían), la compañía explota el territorio nacional sin dejar beneficios reales al crecimiento económico del país, donde su único aporte real es la generación de empleo, que dicho sea de paso no era la mejor pagada en esa época, ya que "mientras la construcción de carreteras pagaba entre 0.50 y 1.25 centavos de dólar, la minería pagaba entre 0.37 centavos y 1 dólar" (Molina-Chocano 73). Todo esto era legal, debido a las reglas establecidas por las autoridades gubernamentales, con lo cual la compañía era independiente de decidir cómo explotar los recursos y cuánto devolver a la economía nacional de las grandes utilidades logradas con la explotación de los recursos minerales, acuíferos y humanos de nuestro país.

A pesar de su constitución como una empresa capitalista típica, el hecho de que en su funcionamiento adoptara la modalidad de un enclave en el país, restringió sensiblemente su impacto en la estructura productiva del país, en la medida en que no ofreció una contribución significativa a la dinámica interna de la economía, como sí lo hicieron en términos relativos o al menos parcialmente otras explotaciones menores. Su efecto principal se expresó más bien en un cierto nivel de generación de empleo. Las exenciones fiscales concedidas impidieron que el Estado participara razonablemente de las considerables utilidades generadas, restringiéndose con ello la expansión del Tesoro Público y la ampliación del escaso nivel de capitalización de la economía nacional (Molina-Chocano).

El proceso de concesión de territorio a la Rosario por parte del gobierno y su posterior autotransformación de una compañía a un enclave, se replicaron a lo largo 
de todas las grandes concesiones mineras otorgadas desde entonces hasta la actualidad. En pleno siglo XXI, las concesiones mineras siguen siendo parte de la agenda de desarrollo de los actuales administradores de la política de Honduras; sin embargo, se ha comprobado que el aporte del rubro minero a la economía nacional es insignificante al compararlo con otros sectores de la economía hondureña, ya que "entre el 2000 y el 2015, la minería contribuyó, en promedio, menos del $1 \%$ anual al PIB, y fue el sector que empleó la menor cantidad de mano de obra en Honduras" (OXFAM 7). Complicando aún más esto, las consecuencias ambientales y sociales de la mala praxis de algunas compañías mineras son otro ejemplo de la política del enclave aplicada en este tipo de concesiones; el ejemplo más nefasto es la explotación a cielo abierto realizada en la "Mina de San Martín" en el Valle de Siria de Honduras.

La explotación minera a cielo abierto en el Valle de Siria, donde está ubicado el Proyecto San Martín a cargo de la empresa Entre Mares Honduras, filial de la canadiense Gold Corp, que obtuvo concesiones por una extensión máxima de 118.000 hectáreas y terminó afectando de manera directa e indirecta a las comunidades de Cedros, Marale, San Ignacio, El Porvenir y Palo Alto (Equipo Nikzor).

Este modelo de enclave ha sido el más longevo y utilizado en la historia de este país y, desde el año $2013,^{10}$ los actuales administradores del país están dispuestos a ampliar este tipo de concesionamientos a cualquier costo. Para el caso, hasta octubre del 2015 se concesionaron $964 \mathrm{~km}^{2}$ del territorio nacional, pero de mantenerse la tendencia que lleva la política minera actual se proyecta que este número se puede cuadriplicar a mediano plazo a $4425 \mathrm{~km}^{2}$ (Palma-Herrera, 2018).

El tercer modelo de enclave originado por concesión de territorio en el país a inversionistas extranjeros es el conocido como "el enclave bananero", el cual en un año superó con creces a su rival minero, ya que, entre 1903 y 1904, el valor de las exportaciones bananeras duplicaba a las mineras; y hasta 1920 esta proporción se mantuvo. Luego, entre 1925 y 1926, se quintuplicó (Murga Frassinetti) y, a partir de ese momento, no había comparación entre ambas exportaciones.

Mucho se ha escrito sobre los "enclaves bananeros", en donde se hace énfasis que fueron concesiones territoriales con una historia tan turbia y corrupta que el escritor estadounidense William Sidney Porter (O. Henry, por su seudónimo de escritor) escribió un libro de sus experiencias de primera mano vividas en Honduras entre 1896 y 1897 con este tipo de concesiones, en su libro Of Cabbages and Kings. Por esta obra se le atribuye al autor la creación del término despectivo "república bananera", con el cual se refiere al país ficticio Anchuria;" ${ }^{11}$ este no era otro más que Honduras.

La concesión del territorio nacional a las empresas norteamericanas bananeras no tiene precedentes durante esa época ni en la actual, ya que más que concesión era entrega desmedida a las compañías a cambio de la instalación de líneas férreas que 
eran explotadas principalmente por dichas empresas. Un ejemplo de esto es la contrata o concesión a la Trujillo Railroad Company, donde el gobierno le da en compensación "en propiedad definitiva, DIEZ MIL HECTAREAS de terreno nacional al lado de la línea férrea o en cualquier parte de Honduras, por cada 20 kilómetros de línea principal o de ramales" (Murga Frassinetti 64). Producto de esta política de "dudoso trueque", las compañías bananeras no solo conservaron vastas extensiones de las mejores tierras hondureñas, sino que también lograban aumentar exponencialmente su plusvalía, gracias a las mejoras realizadas en cuanto al acceso a servicios varios tales como: transporte, agua, electricidad, salud, comercio, entre otros. Por ejemplo, la United Fruit Company llego a poseer 400000 acres de tierras (de las cuales, por lo menos 175000 se obtuvieron sin ningún costo), mientras que para el decenio 1914-1924 el valor de sus tierras en Honduras aumentó a USD 26000000 (Murga Frassinetti). Con lo anterior se puede ver que además de obtener utilidades por el producto bananero, las concesionarias bananeras estaban acaparando el mercado tierras del país, con esto lograron aumentar su propio capital a expensas de Honduras.

La era del enclave bananero de capital norteamericano se originó con la primera contrata o concesión otorgada a la Vaccaro Brothers and Company, bajo el Decreto N. 20 de 1903, dicha compañía se liquidó en 1922 y en su lugar se constituyó la Standard Fruit and Steamship Company (Sánchez), mejor conocida como Standard Fruit Company. De acuerdo con la opinión oficial del gobierno de Honduras, el enclave bananero finalizó en 1975 con la emisión del Decreto N. 253, en el cual se derogan a partir del 15 de septiembre de ese año todas las contratas o concesiones que gozaban las compañías bananeras extranjeras que operaban en Honduras hasta ese momento, entre estas, Tela Railroad Company y la Standard Fruit Company (Ministerio de Cultura, Turismo e Información).

Sin embargo, para muchos estas compañías continuaron su hegemonía en la zona atlántica, mucho después de la cancelación de concesiones, para lo cual simplemente se adaptaron a los tiempos modernos, como explica Sánchez, en 1965 la Standard Fruit Company fue adquirida por la Castle and Cooke Inc., pero mantuvo su nombre, posteriormente, fue comprada por la Dole Food Company. En la actualidad, Honduras forma parte de la red de países productores agrícolas de esta compañía (Figura 5). Hay sectores internacionales que indican que esta compañía mantiene las clásicas políticas de los enclaves bananeros, no solo en Honduras, sino también en otros países donde se encuentra. Siendo el principal reclamo hacia ella: el incumplimiento de condiciones laborales adecuadas y salarios dignos para sus empleados.

Los trabajadores de Dole Food Company en Ecuador, Colombia, o cualquier otro país donde funciona esta multinacional, que necesitan mejores salarios o condiciones de trabajo más dignas no deben tener pelos en la lengua, ni mucho menos pena moral, para exigir estos mejoramientos. Dole tiene suficiente capital para compartir un poco más con sus empleados (Mulligan). 
Figura 5

MAPA DE PAÍSES BANANEROS A FINALES DEL SIGLO XX

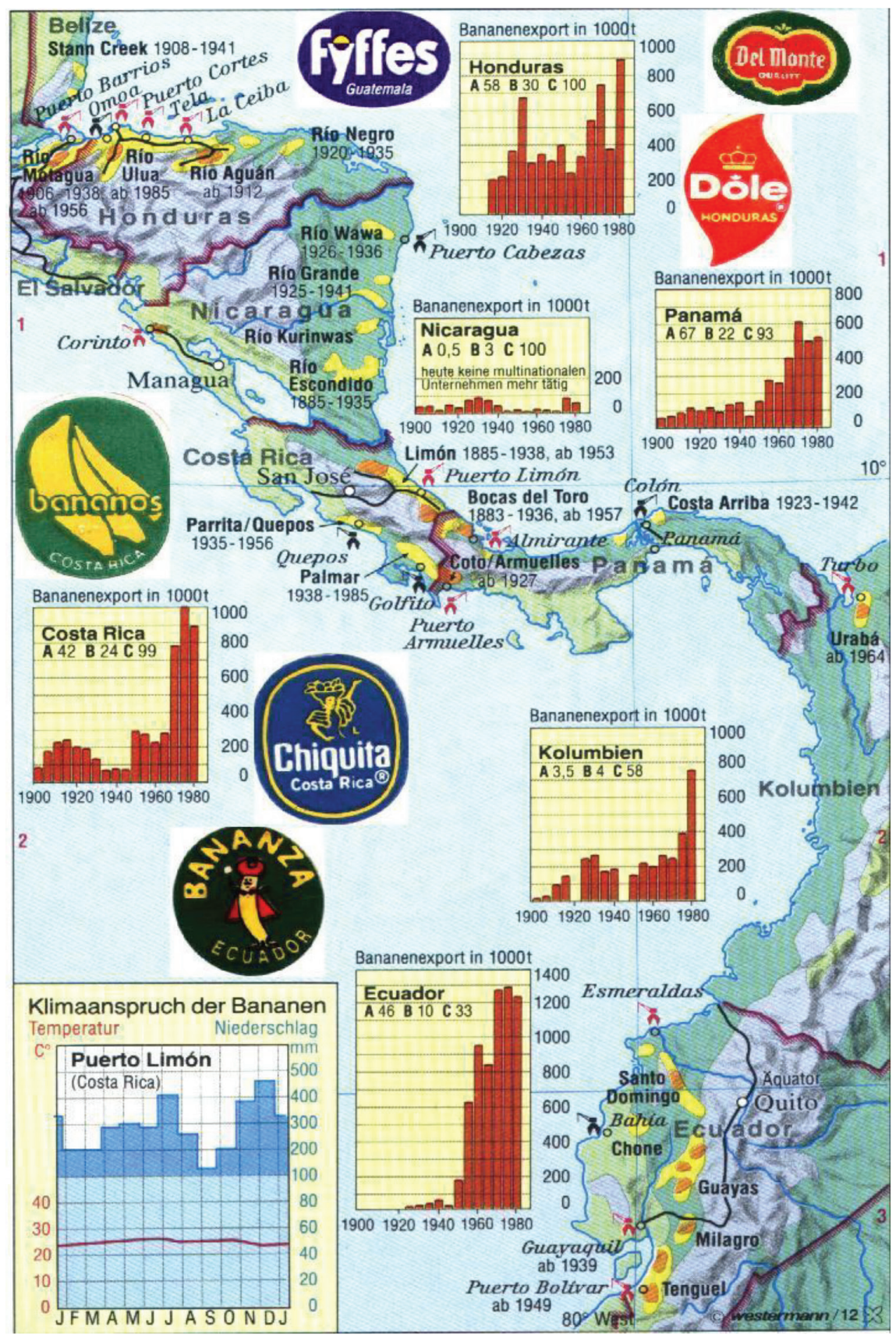

Fuente: Vogeler. 


\section{El primer intento de revivir el primer enclave del siglo XIX}

En un intento por revivir la pasada gloria obtenida con el primer enclave en el Pacífico hondureño, en los inicios de la década de los ochenta del siglo XX, el gobierno de Honduras diseñó y propuso un estudio preinversional para la Isla del Tigre, el cual es, hasta la fecha, el único caso hondureño concreto de planificación de un enclave a través de un estudio y un plan de desarrollo previo a su instalación. Dicho plan de desarrollo proponía zonificar a la isla del Tigre en cinco distritos: residencial, comercial, industrial, uso público y agropecuario/forestal (Figura 6) en base a los modelos de planificación y desarrollo urbano imperantes en esa época.
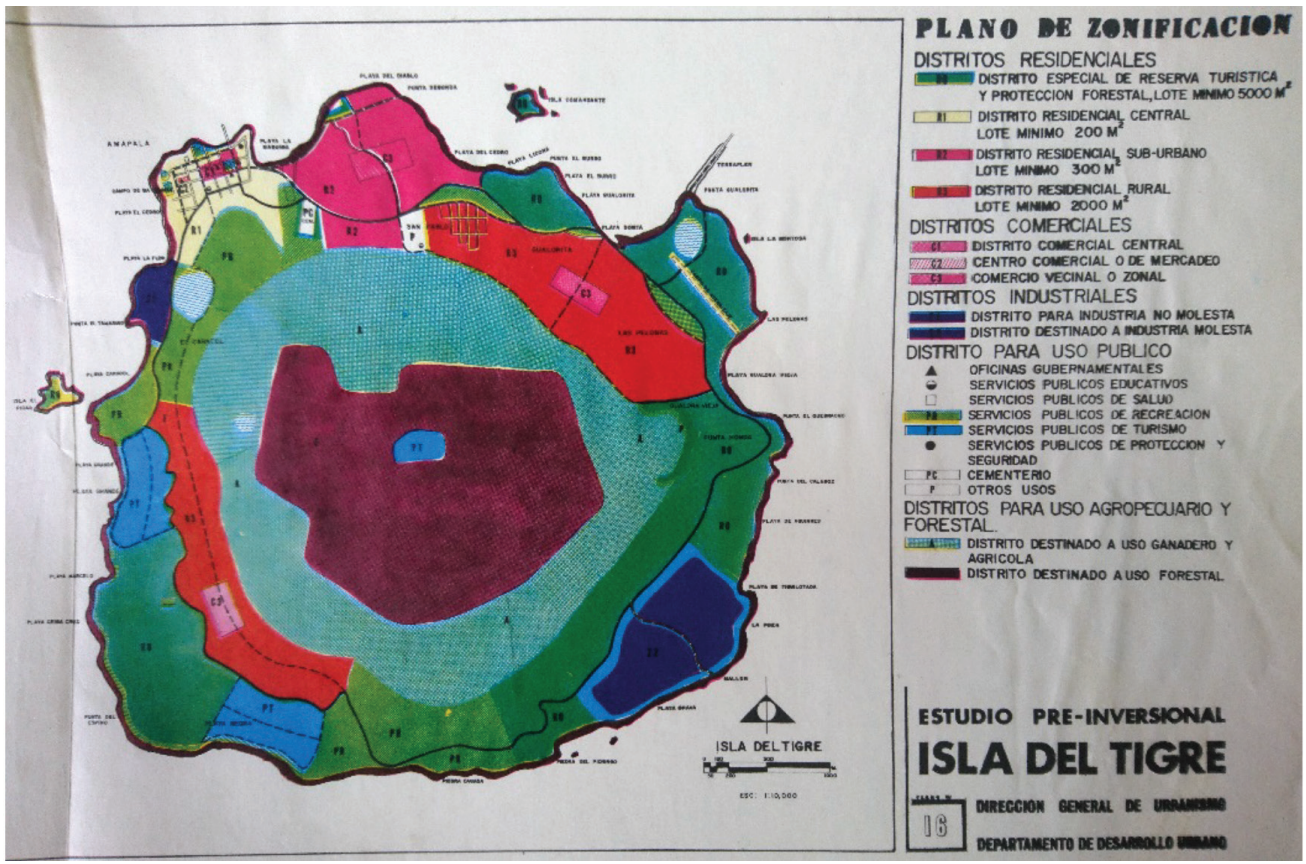

Fuente: Secretaria de Comunicaciones, Obras Públicas y Transporte.

Aunque dicha propuesta consistía en una iniciativa planificada para atraer inversionistas extranjeros, esta nunca se logró concretar, por lo cual quedó simplemente en el papel. Dicho plan pareció ampararse en el régimen especial concedido al Golfo de Fonseca establecido mediante el Art. 10 de la Constitución Nacional para que dicha concesión del territorio no fuera inconstitucional (Congreso Nacional de Honduras). 
Los diseñadores de dicho plan fueron el Consejo Superior de Planificación Económica (CONSUPLANE), en conjunto con el Departamento de Desarrollo Urbano de la Secretaria de Obras Públicas y Transporte (SECOPT). Se puede afirmar que este "primer intento de revivir un enclave" fue el primero en tomar la figura concreta de "crear una ciudad" mediante técnicas de desarrollo urbano para transformar una región rural en una urbe impulsadora de desarrollo y empleo en base a la inversión foránea y los recursos naturales circundantes, es decir, que la figura de una "Ciudad Chárter" en Honduras, ya había sido concebida previamente de manera similar a la idea actual. Esto, como se ha explicado antes, es por la fijación que padecen las elites políticas hondureñas al creer ciegamente en que la concesión del territorio es la manera más rápida, segura y menos costosa de generar desarrollo.

\section{Ciudad chárter: El modelo de desarrollo urbano de Paul Romer}

En el año 2018, Paul Romer ${ }^{12}$ fue uno de los dos galardonados que recibió el Premio Nobel de Economía, de la Real Academia de las Ciencias de Suecia, por su trabajo relacionado con la integración de las innovaciones tecnológicas en el análisis macroeconómico a largo plazo (Nobel Prize). No obstante, antes de ganar este premio tan respetado, la fama de este reconocido economista ya era global por sus teorías controversiales sobre las ciudades chárter, modelo teórico impulsor de desarrollo económico (conocido en Honduras como ciudades modelo o ZEDE). Lo paradójico con este modelo de desarrollo controversial consiste en que, si bien es conocido a nivel mundial, son pocas las personas y entidades en nuestra región que se han interesado en entender a fondo en qué consiste el modelo Charter City. ${ }^{13}$ Para lograr comprenderlo, es necesario abocarse a la literatura de su autor, el cual nos comparte la siguiente definición:

Una Charter City va más allá de una zona económica especial (special economic zone, en inglés), ya que esta aumenta su tamaño a la escala de una ciudad y amplia el alcance de sus reformas. Sus reformas deben extenderse a todas las reglas necesarias para estructurar las interacciones en una ciudad bien administrada y para apoyar el intercambio en una economía de mercado moderna. Las reglas en este contexto abarcan lo que los académicos a menudo denominan "instituciones": las normas sociales y las leyes formales (junto con los sistemas de cumplimiento) que determinan cómo interactúan las personas. Las reglas obsoletas a menudo frenan a las personas. Algunas reglas pueden hacer que sea demasiado fácil ser un criminal o demasiado difícil iniciar un negocio del sector formal. Otras reglas limitan la competencia, por ejemplo, al prohibir que las empresas privadas produzcan y vendan energía eléctrica. Como resultado, los ciudadanos de los países pobres a menudo terminan pagando más por bienes básicos como la electricidad, si es que tienen acceso a ellos (Fuller y Romer). 
En la anterior definición, el autor aclara que una Charter City es similar, pero de manera mucho más amplia, a una "Zona Industrial de Procesamiento para Exportaciones o ZIP" (Zona Económica Especial), es decir, es más complejo que los modelos territoriales que se han aplicado en Honduras para impulsar el desarrollo económico y social en el pasado; explica sobre las debilidades de las ZIP que:

Estas zonas más pequeñas han ampliado el empleo en áreas tales como prendas de vestir y textiles, pero no han traído las protecciones legales mejoradas que se desean por su propio bien y que son necesarias para atraer empleos altamente calificados (Fuller y Romer 9).

Para entender mejor esto, Romer ofrece como ejemplo de la aplicación de su teoría la experiencia de Hong Kong, la cual gracias al apoyo de la gestión británica se convirtió en un exponente mundial de desarrollo. Lamentablemente muchos ven este ejemplo como una muestra indiscutible de cómo se genera un enclave moderno; sin embargo, Romer hace hincapié en que lo que realmente impulsó la economía de Hong Kong, fue el "Know how" que los británicos compartieron. Por ello, Romer explica que el modelo de las ciudades chárter se basa en que uno o varios países desarrollados transmiten su conocimiento de gestión institucional para apoyar la prosperidad económica y el Estado de derecho del país anfitrión.

La propuesta de las ciudades chárter sugiere que los países en desarrollo pueden asociarse con aliados creibles, utilizando zonas de reforma para implementar reglas que se sabe que funcionan bien. Al comenzar en un nuevo sitio, las reglas formales en una ciudad chárter y las normas que estas reglas fomentan pueden diferir notablemente de las que prevalecen en otras partes del país. Sin embargo, estas reglas pueden ser legítimas a los ojos de los migrantes a la zona, al igual que las reglas en un país de altos ingresos son legítimas a los ojos de los pocos inmigrantes admitidos (Fuller y Romer 6).

Podemos intuir que el modelo de ciudad chárter muestra que la única manera en que el "Know How" puede transmitirse, para lograr de forma efectiva la prosperidad económica y el Estado de derecho del país anfitrión, es por medio de la aplicación del "aprender haciendo" en la tierra del "país anfitrión" y bajo la gestión absoluta del "país socio", para garantizar que el estatuto o reglas (chárter) sea respetada y aplicada durante las décadas necesarias para lograr resultados satisfactorios. Igualmente, se requiere recurso humano de un "país origen" calificado para llevar a cabo los proyectos que la ciudad chárter establezca. Esta relación entre actores del modelo se puede representar en el esquema de la Figura 7, basado en los tres distintos roles de las naciones participantes en el modelo, donde cada rol es precedente del anterior y donde cada uno cumple un papel que complementa al otro, todo de una manera lineal. 
Figura 7

LOS TRES DISTINTOS ROLES DE LAS NACIONES PARTICIPANTES:

ANFITRIÓN, ORIGEN Y SOCIO

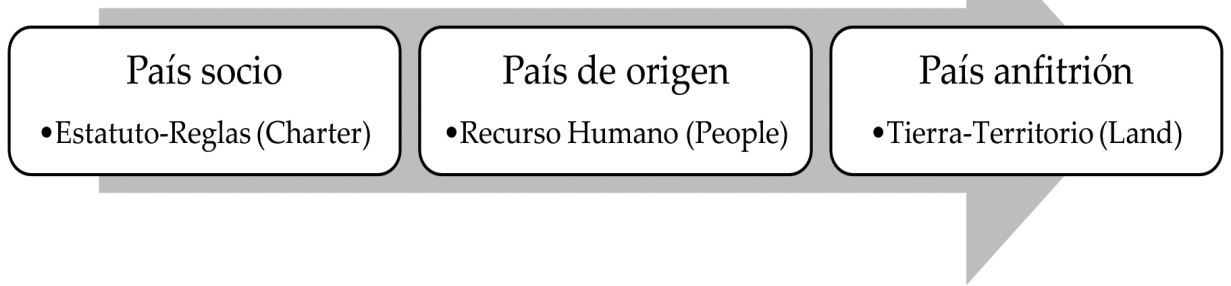

Fuente: Elaboración propia a partir de Fuller y Romer.

Los inversionistas no construyen nuevas fábricas en las regiones del mundo donde la gente está más ansiosa por los empleos del sector formal, sino en lugares donde los insumos no son costosos (electricidad barata, por ejemplo), las personas y las propiedades están seguras (de la delincuencia las primeras y de la inseguridad jurídica las segundas) y las reglas para hacer negocios son sencillas, previsibles y razonablemente eficientes. Aunque las mejores reglas deberían ser fáciles de replicar, la experiencia muestra que los grupos sociales en todas las escalas, desde las empresas hasta las ciudades y las naciones, tienen grandes dificultades para lograr el consenso que se requiere para cambiar sus reglas y normas (Fuller y Romer). Es ahí donde el papel del "país socio" es crucial, puesto que el principal papel de este modelo descansa en uno o varios actores que garanticen que el estatuto o reglas de la ciudad chárter serán respetadas y aplicadas durante las décadas necesarias para que los inversores recuperen su inversión. Para que todo esto se cumpla, el modelo permite una estructura de gobierno que se adapta al contexto regional en el cual se encuentre; sin embargo, el modelo requiere una estructura de gobierno que tenga cuatro elementos básicos: tierra no desarrollada, un estatuto, compromiso de elección e igualdad de trato para todos.

La estructura de gobierno de una charter city puede variar significativamente dependiendo de donde se establezca, pero todas las charter cities compartirían cuatro elementos comunes. El primero es un terreno sin desarrollar que es lo suficientemente grande como para albergar a una ciudad entera. Un buen tamaño objetivo es de 1.000 kilómetros cuadrados, aproximadamente el tamaño de Hong Kong y Singapur. El segundo elemento común es un estatuto que especifica previamente las reglas generales que se aplicarían alli. El tercer elemento es un compromiso de elección, respaldado por la entrada voluntaria y la salida gratuita para todos los residentes, empleadores e inversionistas. El cuarto es un compromiso con la igualdad de trato de todos los residentes bajo la ley (Fuller y Romer). 
Al analizar la relación sobre cómo se complementan los roles de los países y los elementos básicos del modelo de una ciudad chárter (Figura 8), se puede ver que el papel más importante lo ejecuta el país socio, ya que es el responsable del "estatuto" o de las reglas a seguir en la ciudad chárter, el cual es la herramienta principal para asegurar el trato igualitario del recurso humano está a cargo del país origen. Con la aplicación del estatuto para administrar el territorio se genera un elemento más en el modelo, y este es la "seguridad", que va desde la jurídica hasta la ciudadana, la cual es crucial para invertir en cualquier lugar del mundo. A la vez, el recurso humano del país origen es atraído por un territorio donde existe "libertad" para elegir invertir recursos económicos, labor humana y/o conocimiento profesional. Mediante el esque$\mathrm{ma}$, se puede visualizar que acoplarse todos los roles y elementos forman lo que se conoce como "Estructura base del gobierno de una Charter City".

Figura 8

RELACIÓN ENTRE LOS ROLES DE NACIONES PARTICIPANTES

Y LOS ELEMENTOS BÁSICOS DE UNA CIUDAD CHÁRTER

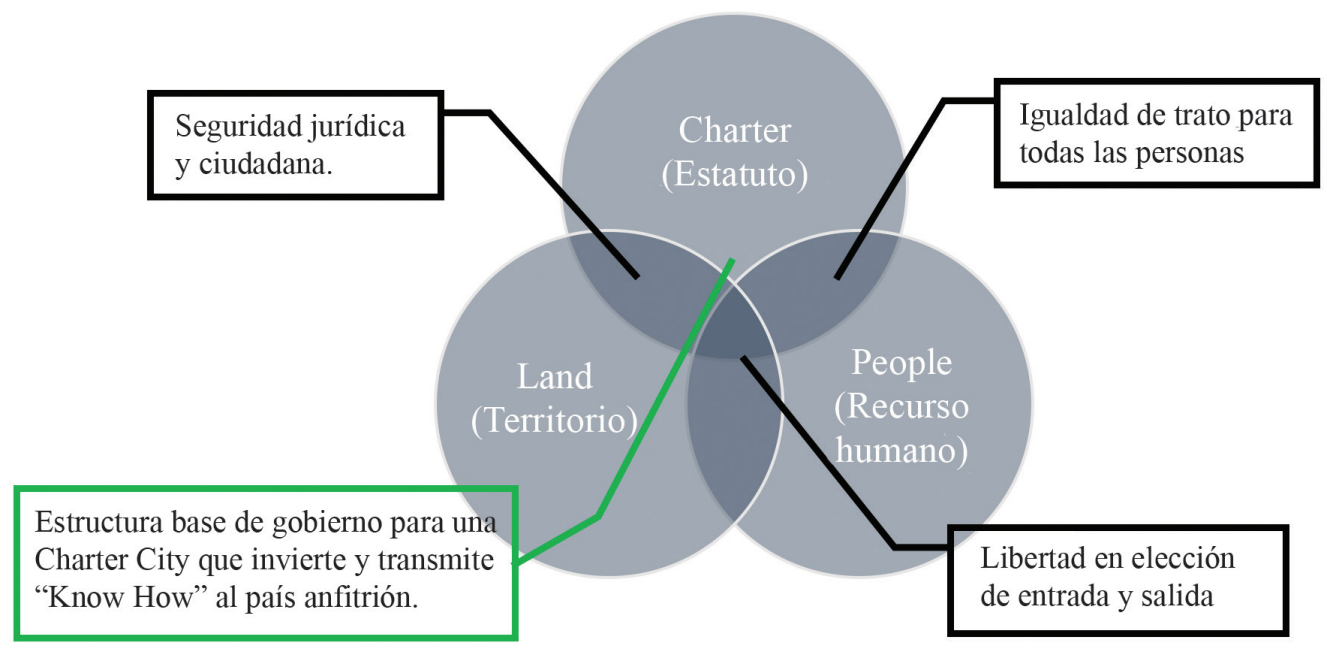

Fuente: Elaboración propia a partir de Fuller y Romer.

Con lo expuesto en esta sección, se puede ver que la teoría del modelo económico de Paul Romer posee una visión economista que busca fomentar el desarrollo económico y social a través de un "país socio", cuya principal característica se centra en ser una nación desarrollada que está dispuesta a compartir su experiencia de gestión con el "país anfitrión". Se puede deducir que la principal condicionante de que el país anfitrión apruebe y apoye de manera oficial y transparente la estructura gubernamental de una Charter City. 
Si el modelo de las ciudades chárter de Paul Romer ofrece desarrollo al país anfitrión que lo acobija o si es una forma moderna de retomar los enclaves, solo su aplicación nos podría dar una respuesta real. Por esta razón, cuando se mencionaba que Honduras aplicaría este modelo en su territorio, los ojos del mundo se pusieron sobre esta nación. Hasta el momento ha pasado una década desde que se iniciaron las gestiones para crear la primera ciudad chárter en Honduras y lo único que sabemos es que todavía no se materializa como tal; es uno de los más grandes "secretos de Estado" al cual nadie puede acceder.

\section{Los enclaves como opción de desarrollo durante la crisis política de Honduras en el siglo XXI}

Antes, durante y después del golpe de Estado del 2009, ha existido una crisis política continua y decadente, caracterizada por la continuidad en el poder de un partido político específico y que no da muestras de ceder oportunidad a otros de administrar los recursos del país. Una década se cumple desde que un partido político específico ha controlado el rumbo del país y parece ser que su mayor estrategia de desarrollo es otorgar al mejor postor partes del territorio nacional. Esto, sumado a los antecedentes de enclaves anteriormente expuestos, demuestran que no es nada innovador que políticos hondureños concesionen su territorio a inversionistas extranjeros con el supuesto objetivo de generar desarrollo económico a los habitantes de este país. Por ello, la política concesionaria de las Zonas de Empleo y Desarrollo Económico no es ni nueva ni es exclusiva de los gobiernos actuales.

\section{Las Regiones Especiales de Desarrollo (RED)}

Basados en la teoría de las ciudades chárter de Paul Romer, la administración nacionalista creo las Regiones Especiales de Desarrollo, las cuales, desde antes de su supuesta legalización se les acuñó el término popular "ciudades modelo".

La idea original del economista Paul Romer consistía en apoyar la creación de una ciudad en Honduras, la cual ofreciera las oportunidades que buscan las personas que migran de manera ilegal a los Estados Unidos, de esta manera, las familias ya no se separarían y podrían estar juntas y seguras. Esta idea buscaba ser una innovadora opción para solucionar el problema de la migración ilegal e insegura, la cual ha sido vista como la opción más viable para solucionar los problemas económicos por las familias de escasos de nuestro país ante la falta de opciones y oportunidades.

Una nueva ciudad en Honduras podría crear oportunidades importantes. Cada año, aproximadamente 75000 personas salen de Honduras en busca de trabajo en los Estados Unidos. Muchos van sin sus familias. Alrededor de 10,000 de ellos son secuestrados en el camino y retenidos para obtener un rescate. Muchos de los que llegan a Estados Unidos viven con miedo a la deportación (Romer). 
En el año 2011, mediante la publicación del Decreto Legislativo 123-2011, se crean las RED (mejor conocidas como ciudades modelo), con el supuesto propósito de mejorar las condiciones de vida de los hondureños mediante dos estrategias: primero, la aceleración en la adopción de tecnologías que permitan "producir" con alto valor agregado; y segundo, la generación de empleos.

Para el 2012, ya se habían definido la localización de las primeras RED; estas se ubicaron estratégicamente cerca de las costas y en varios lugares donde ya existía una base previa de explotación agrícola, industrial o comercial. Dichas zonas fueron tres: la zona del Valle de Sula, la zona del Golfo de Fonseca y la zona de Punta Castilla y Valle de Sico y Paulaya (Figura 9). La definición de esta última zona RED, la cual es ampliamente habitada por la población garífuna hondureña, hizo que las organizaciones de derechos humanos y a la comunidad indígena del país reaccionaran e "interpusieron 68 recursos de inconstitucionalidad y una acusación por traición a la patria en contra de los 126 diputados. En octubre 2012, el pleno de la Corte Suprema de Justicia se pronunció con 13 (de 15) magistrados en contra" (Equipo Nikzor). Después de estos sucesos, las iniciativas para impulsar las RED se ralentizaron, hasta que en el 2013 evolucionaron para convertirse en las ZEDE.

Figura 9

UBICACIÓN DE LAS RED O CIUDADES MODELO EN EL 2012

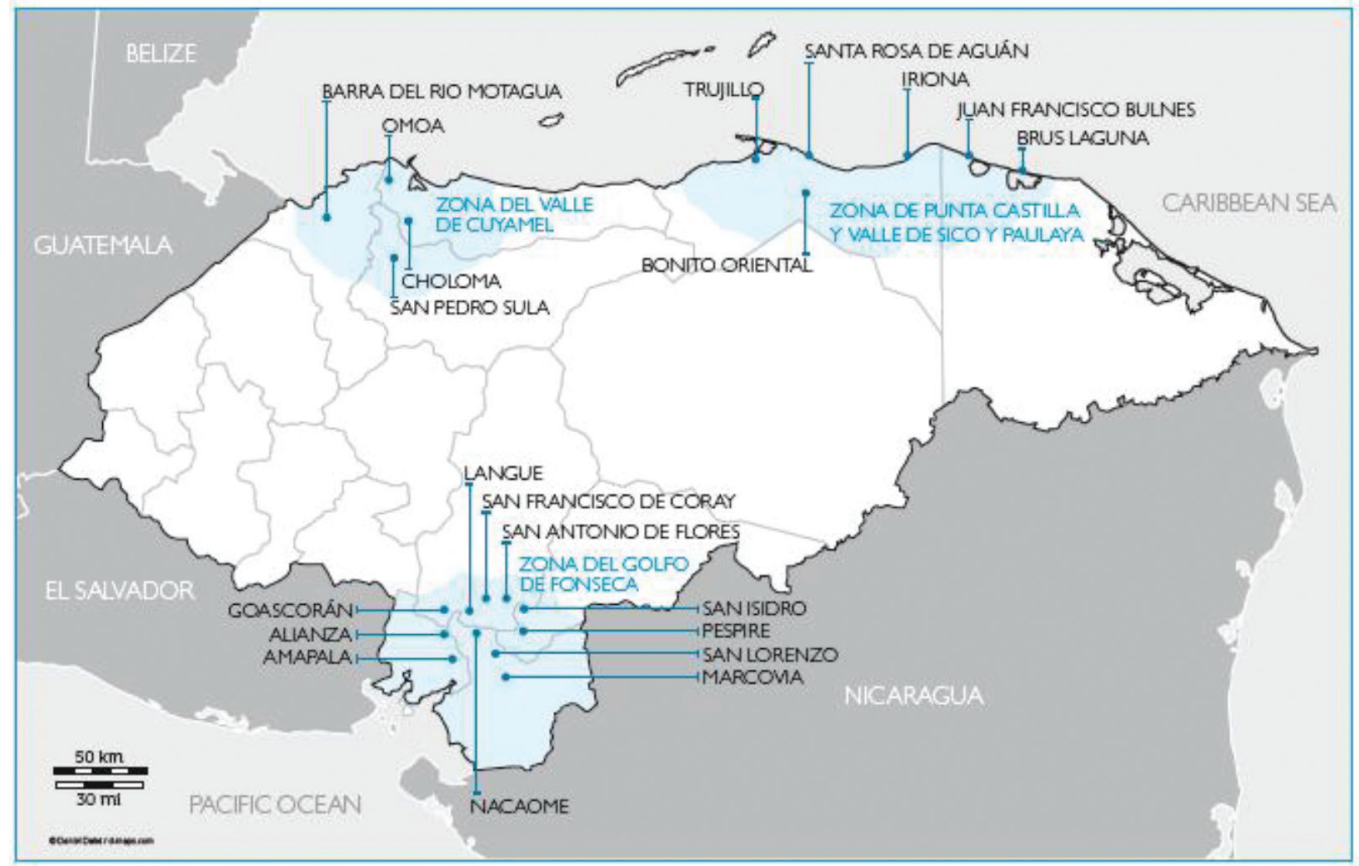

Fuente: Equipo Nikzor. 


\section{Las Zonas de Empleo y Desarrollo Económico}

De acuerdo con la experiencia ganada con el fracaso de las RED, ante el abrumador rechazo de las ciudades modelo de organismos de derechos humanos, comunidad indígena y la propia Corte Suprema de Justicia, el Gobierno central apoyado por el Congreso Nacional a través de su presidente, el abogado Juan Orlando Hernández, hicieron los arreglos necesarios para generar una segunda versión bien escudada legalmente de las RED. A esta versión de las ciudades chárter se les nombró ZEDE. Este cambio de nombre se realizó con dos objetivos: el primero, hacer olvidar a las RED; y segundo, ampliar los objetivos de las ciudades modelo a no solo impulsar desarrollo económico, sino también generar empleo.

Debido a la política totalitarista ${ }^{14}$ que caracteriza las últimas administraciones gubernamentales de Honduras, las cuales se caracterizan por concentrar toda la estructura gubernamental de los tres poderes en un solo mando, el presidencial, es comprensible entender por qué se aplicó la misma doctrina al modelo de las ciudades chárter de Paul Romer.

La figura de las ciudades modelo o ZEDE no está amparada por la Constitución de Honduras, por tal razón en el año 2013, a través de un decreto legislativo, se reformaron aquellos artículos que hacían inconstitucional esta figura territorial, como se puede apreciar en la Tabla 1. Con esto, la figura de los municipios y su autonomía es desplazada por este nuevo esquema territorial a nivel administrativo, financiero y judicial. Todo esto con la finalidad de dar un tinte de constitucionalidad a la nueva figura administrativa territorial nombrada ZEDE. 
Tabla 1

ARTÍCULOS REFORMADOS EN LA CONSTITUCIÓN DE LA REPÚBLICA PARA LAS ZEDE

\begin{tabular}{|c|c|c|}
\hline Artículo reformado & $\begin{array}{l}\text { Objetivo del artículo } \\
\text { de la constitución }\end{array}$ & $\begin{array}{l}\text { Reforma impulsada } \\
\text { en favor de las ZEDE }\end{array}$ \\
\hline 294 & $\begin{array}{l}\text { 1. Establece que las únicas figu- } \\
\text { ras administrativas territoria- } \\
\text { les son los departamentos y } \\
\text { municipios. } \\
\text { 2. Establece la autonomía de los } \\
\text { municipios. }\end{array}$ & $\begin{array}{l}\text { Agrega una nueva figura adminis- } \\
\text { trativa territorial; zonas sujetas a } \\
\text { regímenes especiales por creación } \\
\text { del Congreso Nacional en base al } \\
\text { Art. } 329 \text { reformado. }\end{array}$ \\
\hline 303 & $\begin{array}{l}\text { Establece las figuras que inte- } \\
\text { gran el Poder Judicial. }\end{array}$ & $\begin{array}{l}\text { Agrega una nueva figura judi- } \\
\text { cial; tribunales exclusivos para las } \\
\text { ZEDE. }\end{array}$ \\
\hline 329 & $\begin{array}{l}\text { Establece que el Estado promue- } \\
\text { ve el desarrollo económico y } \\
\text { social. }\end{array}$ & $\begin{array}{l}\text { Agrega la figura de la ZEDE como } \\
\text { promotora del desarrollo económi- } \\
\text { co y social (de ahí su nombre), con } \\
\text { los siguientes beneficios: } \\
\text { 1. Personería jurídica. } \\
\text { 2. Régimen fiscal especial. } \\
\text { 3. Independencia para celebrar } \\
\text { contratos sin límite de tiempo y } \\
\text { gobierno de turno. } \\
\text { 4. Autonomía funcional y admi- } \\
\text { nistrativa. } \\
\text { 5. Las mismas funciones, facul- } \\
\text { tades y obligaciones de un } \\
\text { municipio. }\end{array}$ \\
\hline
\end{tabular}

Fuente: Elaboración propia a partir de la Ley ZEDE.

De acuerdo con la Ley de las ZEDE, estas han sido creadas "con el propósito de acelerar el cumplimiento de las metas del Plan de Nación y facilitar condiciones que permitan al país la inserción en los mercados mundiales bajo reglas altamente competitivas y estables" (Congreso Nacional de Honduras, Ley Orgánica A57). La misma Ley proporciona los tipos de zonas que pueden generarse, gracias a esto se puede crear una clasificación de estas, hasta agruparlas en cuatro grupos de concesión que pueden otorgar las ZEDE. Este tipo de concesiones son para aprovechamiento de: banca y finanzas, comercio, territorio y recursos naturales. Como se puede apreciar 
en la Figura 10, los cuatro tipos de concesiones que se logran con las ZEDES pueden categorizarse a su vez en dos tipos de concesiones:

- Concesiones comerciales y financieras

- Concesiones territoriales y de recursos naturales

Figura 10

CLASIFICACIÓN DE ZEDE POR TIPOS DE CONCESIONES SEGÚN LA LEY ZEDE

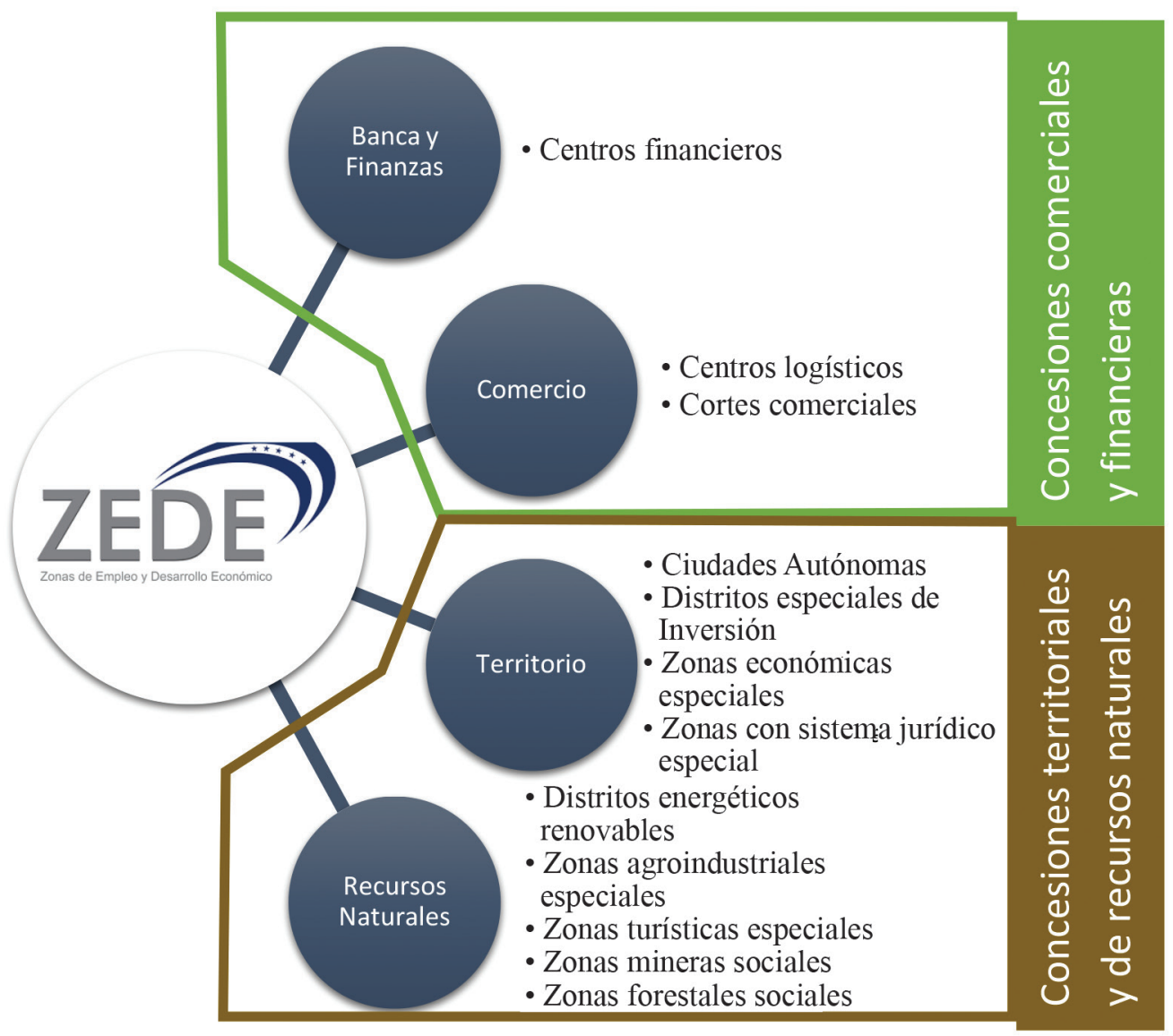

Fuente: Elaboración propia a partir de Decreto Legislativo 120-2013.

Las ZEDE a ejecutarse se desarrollarán en los siete departamentos de los litorales del Atlántico y Pacífico (Figura 11), esta localización geográfica es parte de satisfacer la necesidad de estar conectados a través de rutas no solo terrestres, sino también marítimas para sus actividades de conexión internacional. A la vez, el único indicador que maneja la Secretaria de Desarrollo Económico (SDE) para mostrar el impacto de 
esta política de enclave es "la generación de 200,000 empleos a lo largo de varios años" (Redacción, 2017). Como ya se explicó anteriormente, esta es una estrategia para desplazar los indicadores de medición, con el fin de verificar si estas ciudades modelo alcanzan o no el desarrollo económico prometido (el cual requiere mayor inversión de recursos y tiempo) y sustituirlos por un simple indicador de medición de puestos de empleo generados, lo cual es mucho más fácil de producir y cuantificar sin tomar en cuenta si estos son de calidad o no, si son temporales o permanentes, si ofrecen los derechos laborales respectivos, o bien, si pagan el salario mínimo o menos.

Figura 11

UBICACIÓN GENERAL DE LAS ZEDE

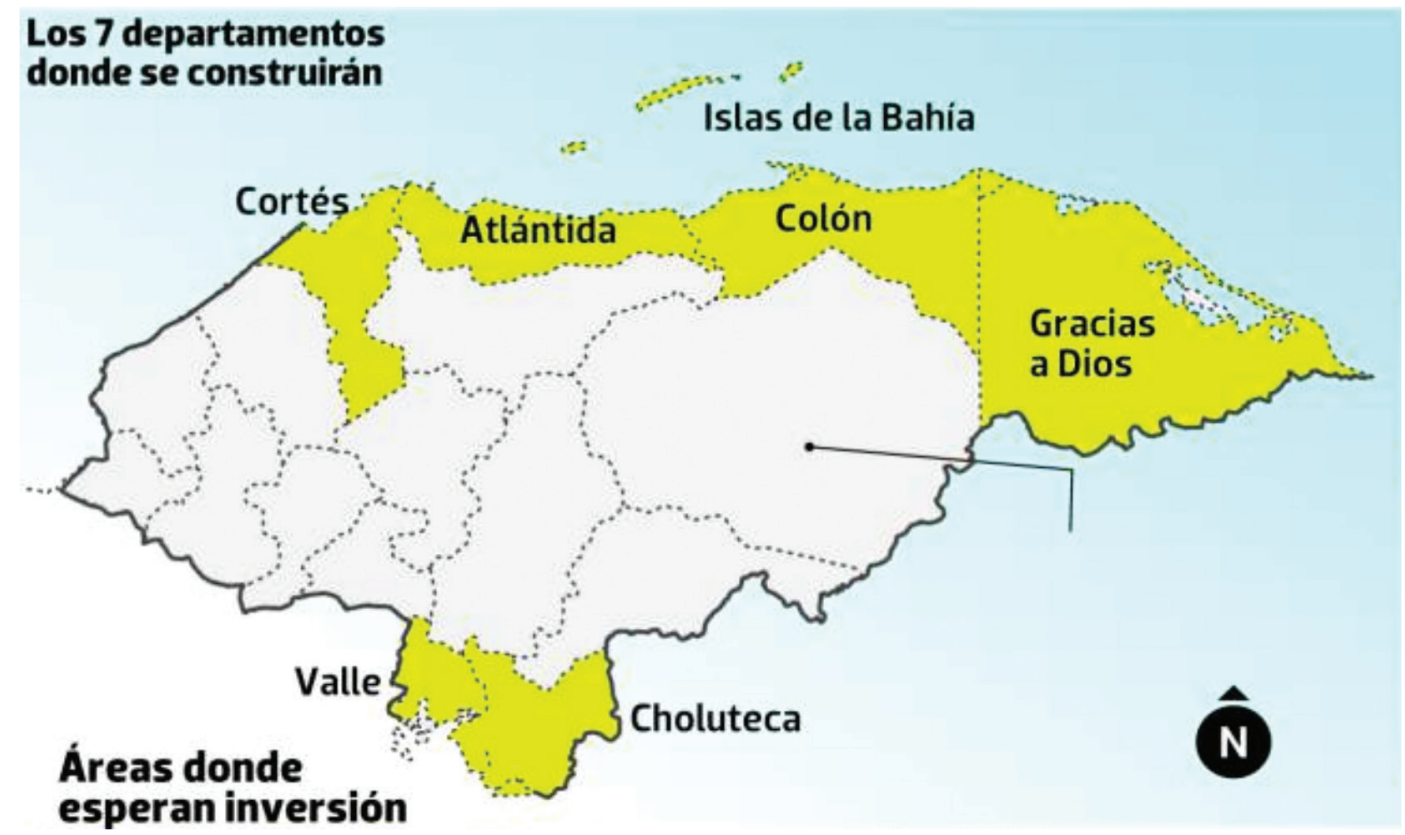

Fuente: Redacción, 2017.

Al comparar la localización de las ZEDE con la ubicación de los municipios más pobres o con mayor índice de pobreza (Figura 12), se descubre que las ZEDE no se instalarán en los departamentos donde se concentra la peor pobreza del país, es decir, donde son más necesarias. Dichos departamentos son Lempira, Intibucá, La Paz, entre otros. A la vez, se puede apreciar que las ubicaciones de las ZEDE son exactamente las mismas de las RED, lo cual nos demuestra la carencia de estudios innovadores o sociales que busquen tener un verdadero impacto en la reducción de la pobreza del país con esta política concesionaria. 


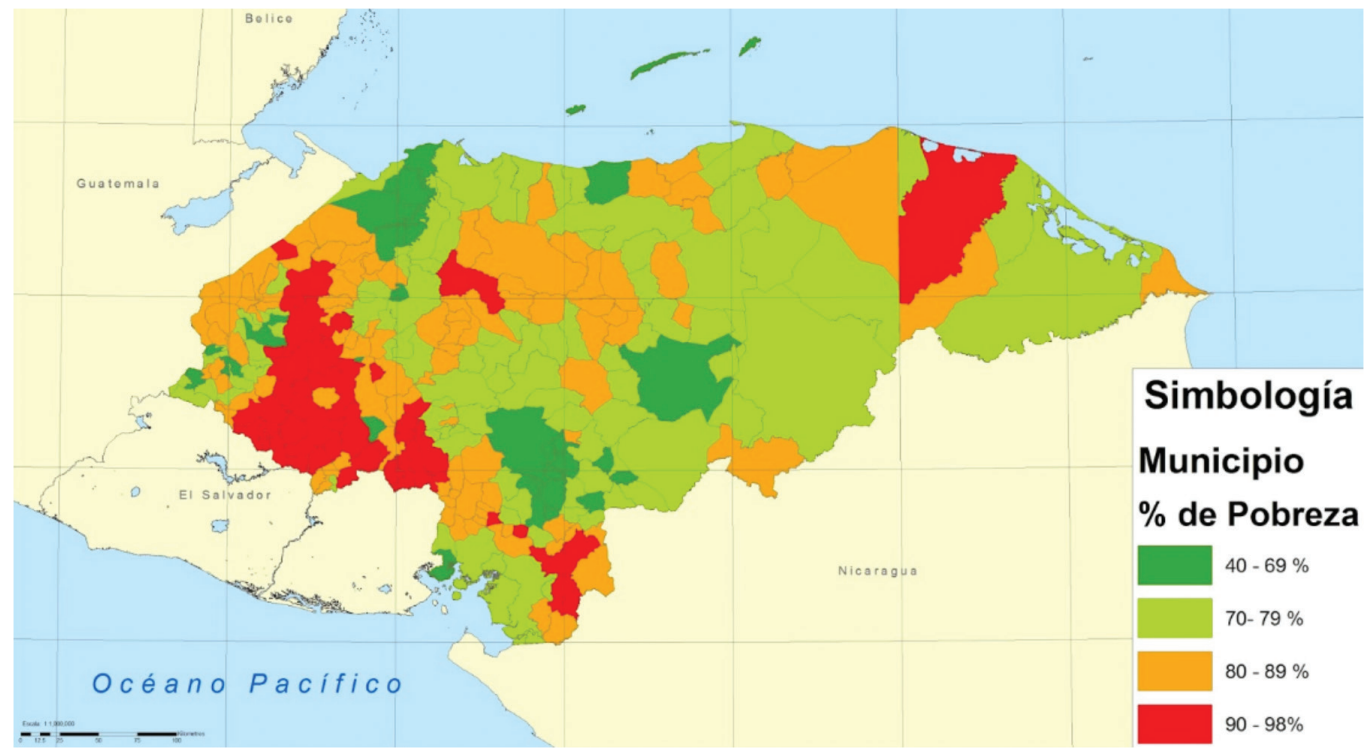

Fuente: FOSDEH.

\section{Las Zonas de Empleo (Zede)}

Acerca del cambio de nombre de RED a ZEDE, parecía ser una mejora a todas luces, lamentablemente la intención política de este cambio radicaba en ejecutar el primero de dos pasos para cambiar los indicadores de medición de impacto de las ciudades modelo propuestas, ya no serían indicadores de desarrollo económico, sino simplemente número de empleos generados. Lo anterior porque crear indicadores de impacto basados en la cuantificación de empleos (independientemente de que sean empleos dignos o no) es mucho más rentable políticamente que utilizar indicadores que midan el desarrollo económico, puesto que estos son más complejos al depender de muchas variables y requieren mayor inversión de recursos financieros y tiempo, lo cual no es factible políticamente. Esto se evidencia en la publicación del informe de logros de la presidencia en el periodo 2014-2017'15 (Presidencia de Honduras). En dicho informe se puede apreciar cómo las ZEDE son llamadas ahora simplemente "Zonas de Empleo", para dar hincapié al hecho de que la prioridad es simplemente cuantificar nuevos empleos.

En cuanto a la localización de estas ciudades modelo que actualmente les dan el nombre de "cluster", por tercera vez consecutiva las autoridades políticas del país presentan la ubicación de las nuevas ciudades modelo, por lo cual en el 2017 el gobierno 
publica las localizaciones de los cluster, donde se mantienen algunas y se agregan otras nuevas, por ejemplo: Olancho, Santa Bárbara y Comayagua. Sin embargo, la estrategia de aplicar esta política, de llevar desarrollo a zonas que ya tienen iniciativas de desarrollo en proceso o consolidas, es obviamente demagógica.

A pesar de que a partir del 2017 se ha renombrado a las Zonas Especiales de Desarrollo y Empleo como Zonas de Empleo, este cambio parece ser puramente superficial, ya que no existe hasta el momento ningún respaldo legal, ya sea como Decreto, Plan Gubernamental o documental cualquiera, para que se derogue la figura de ZEDE y se sustituya por las Zonas de Empleo. Por lo tanto, si a partir de este momento se llamarán Zonas de Empleo o ZEDE o ambas, esto no tendrá importancia, ya que lo que realmente importa es el cambio de los indicadores de medición de impacto de estas zonas, donde la prioridad es simplemente medir empleos generados, el cual ha sido históricamente el único beneficio realmente medible de los enclaves desde hace generaciones.

\section{El segundo intento de revivir el primer enclave del siglo XIX}

Entre los años 2016 y 2017, como parte de la estrategia de las ZEDE, el Korean Maritime Institute (KMI) y otras organizaciones coreanas realizaron un "estudio preliminar de viabilidad del desarrollo portuario de Amapala", esto gracias a fondos de la Agencia de Cooperación Internacional de Corea (KOICA). Dicho estudio incluyó un diseño preliminar para acondicionar a la Isla del Tigre con infraestructura para albergar un puerto con instalaciones logísticas para alcanzar mercados internacionales aprovechando su adecuada profundidad en su bahía oeste (22.60 metros). El diseño preliminar incluye tres puntos de descarga, almacenes y estacionamiento de descarga. A la vez, se planifica construir un puente para unir esta isla con el territorio continental y así lograr la conexión con el Corredor Logístico o Canal Seco que conecta el litoral Atlántico con el Pacifico (Redacción, 2017). 


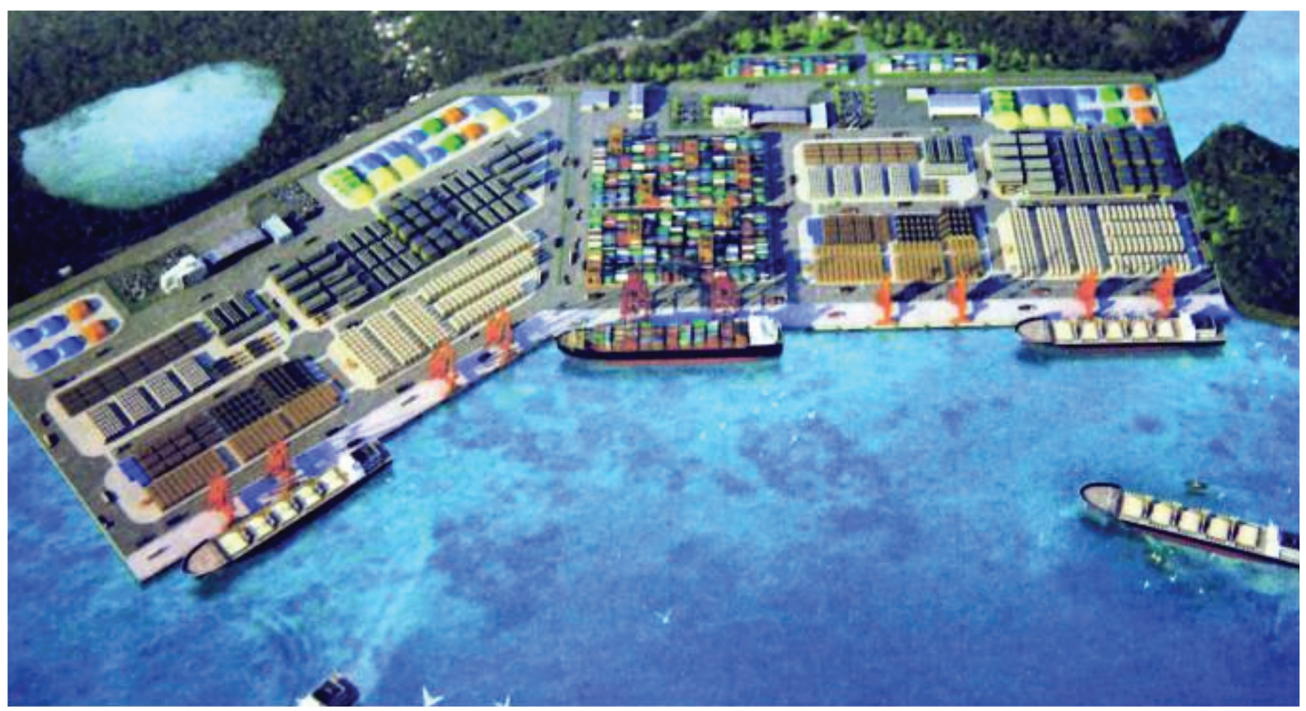

Fuente: Redacción, 2017.

A diferencia del primer intento de revivir el antiguo enclave del Golfo de Fonseca, la finalidad de este proyecto no es integral, ya que hasta el momento las referencias muestran un plan para la construcción de un puerto marítimo sin tomar en cuenta los impactos en el ambiente y comunidades de la isla y el resto del Golfo. Ya que el nuevo y moderno puerto requerirá recursos disponibles en una zona urbana desarrollada para satisfacer industrias, sistemas de transporte, viviendas y servicios varios, pero que no están disponibles en la zona actual. Un plan de desarrollo urbanoterritorial es requerido para reducir los impactos negativos y asegurar un desarrollo en la región de manera sostenible e inclusiva. Sin embargo, como este proyecto portuario beneficiara al Golfo y sus habitantes, no es una prioridad para el poder político que gobierna el país desde hace varios años de manera continua.

\section{Resultados: Las consecuencias de los enclaves en Honduras}

Sobre el Puerto Franco de Amapala, el primer enclave en la República de Honduras, cualquiera puede asimilar el terrible impacto en la soberanía nacional debido al despojo de parte de su territorio isleño en el Golfo de Fonseca; sin embargo, esta concesión territorial nos mostró, por primera vez en la historia, que los enclaves, además de apropiarse de grandes extensiones de territorio, también producen daños de impacto ambiental, ya que este fue documentado, mas no cuantificado. Se menciona que la 
matanza de la fauna mamífera era cotidiana por parte de los habitantes del enclave, al punto de llegar al exterminio de especies, puesto que:

La isla... esta[ba] densamente poblada de bosques donde abunda[ba] la caza. Con frecuencia se mata[ban] venados y otros animales, y los primeros pobladores del puerto a menudo vieron tigres que huían del intruso y se refugiaban en la selva. Estos han sido totalmente exterminados (Wells 105).

Pero no solo la fauna fue afectada, sino también los bosques, ya que, a pesar de ser una concesión comercial, al poseer total autoridad sobre los territorios isleños, se dio provecho a todos sus recursos. Incluso, este aprovechamiento del bosque se extendió, sin ninguna supervisión ni control de parte de las autoridades nacionales, debido a la total independencia que daba este enclave.

[En Amapala] se halla el único aserradero de la costa del Pacifico de Honduras... [donde] importaron la maquinaria de New York... [para] convertir en tablas la madera que llegaba de las costas vecinas... cuya mayor parte es de cedro de magnifica calidad... Las trozas se cortan con sierras largas en las desembocaduras de los ríos Choluteca y Goascorán, y de allá se arrastran por medio de bongos hasta el aserradero (Wells 11).

El modelo de enclave minero, si bien es el segundo tipo de concesión territorial más antiguo y el que perdura hasta nuestros días, es el modelo que ha evolucionado acorde con los males característicos de uno de los países más peligrosos del mundo. ${ }^{16}$ Es muy conocido que las grandes concesiones mineras se convierten en enclaves en los municipios donde se encuentran; sin embargo, también sucede que las pequeñas concesiones mineras producen este efecto a nivel micro.

De acuerdo con Middeldorp, existen casos de minería artesanal, donde esta figura de explotación minera puede llegar a convertir a algunas regiones rurales en pequeños enclaves mineros donde las autoridades "brillan por su ausencia" y se pueden cometer cualquier clase de atrocidades contra la vida humana de quien se oponga a la minería, atrocidades que van desde el secuestro de observadores internacionales hasta el brutal asesinato de inocentes por grupos armados. Y es aqui, donde aparecen estos grupos armados, que el uso de armas para explotar el mineral es común (Citado en Palma-Herrera, 2018).

Mientras el enclave bananero norteamericano nos demostró que las concesiones territoriales pueden hacer que los concesionarios extranjeros se conviertan no solo en ocupantes temporales, sino también en propietarios permanentes de grandes extensiones de las mejores y más valiosas tierras nacionales, con lo cual estos pueden tener una gran influencia en los mercados de tierras del país. A la vez, se observa que pueden tener la capacidad de desplazar cualquier tipo de ocupante de ese territorio, ya sean comunidades rurales, competidores de pequeña escala, entre otros. 
[Durante el enclave bananero] dos compañias privadas tuvieron la concesión y control de 230,000 hectáreas en 1960, posteriormente en 1975 este número bajo a 122,819.10 hectáreas, de las cuales el $76 \%$ (93,242.40 hectáreas) paso de simple concesión a dominio pleno, es decir, que pasaron legalmente a ser dueños privados de las tres cuartas partes de las tierras concesionadas en unos pocos años (Slutzky y Alonso).

Lo que Slutzky y Alonso indican debe recordarnos que una simple concesión territorial puede pasar fácilmente al dominio pleno de los inversionistas, por lo cual la negación del gobierno de esta posibilidad es refutada con estos datos comprobados y documentados. Cualquier concesión puede pasar a ser propiedad privada de sus inversionistas con la simple aplicación de la compraventa de tierras.

La economía del enclave durante la época de las bananeras ya ha dejado una experiencia clara de que se puede esperar de las ZEDE. Ya que, con el banano Honduras realizó un segundo intento de vinculación al mercado mundial, luego de su efímero éxito a través de la exportación minera. Del enclave del siglo anterior, la experiencia ganada fue que los inversionistas extranjeros de enclave contribuyen muy poco al desarrollo económico nacional.

La contribución del Enclave al desarrollo de Honduras fue unidireccional hacia la economía de origen del capital foráneo, en las economías receptoras el impacto económico fue positivo, sin embargo, en la economía local, los ingresos generados por este sector no tuvieron efectos dinamizadores, debido a que la vinculación entre el enclave y la economía local fueron mínimas. Si bien es cierto, que el enclave pagaba impuestos por sus actividades económicas, estos fueron relativamente bajos mientras que sus ganancias obtenidas eran exportadas masivamente. Y desde el punto de visto social, las compañias bananeras marcaron un retroceso (Del Cid 11).

El concesionamiento territorial a inversionistas extranjeros a cambio de lograr el desarrollo económico y social de un país es la base de la teoría de la economía del enclave, muy conocida en el siglo XX y parte del siglo XXI. Al tabular la información resultante del presente estudio, se pueden apreciar la cantidad, tipos, periodos y características de los seis modelos de enclave que históricamente han existido o se han intentado crear en Honduras a través de la figura de la concesión del territorio (Tabla 2). 


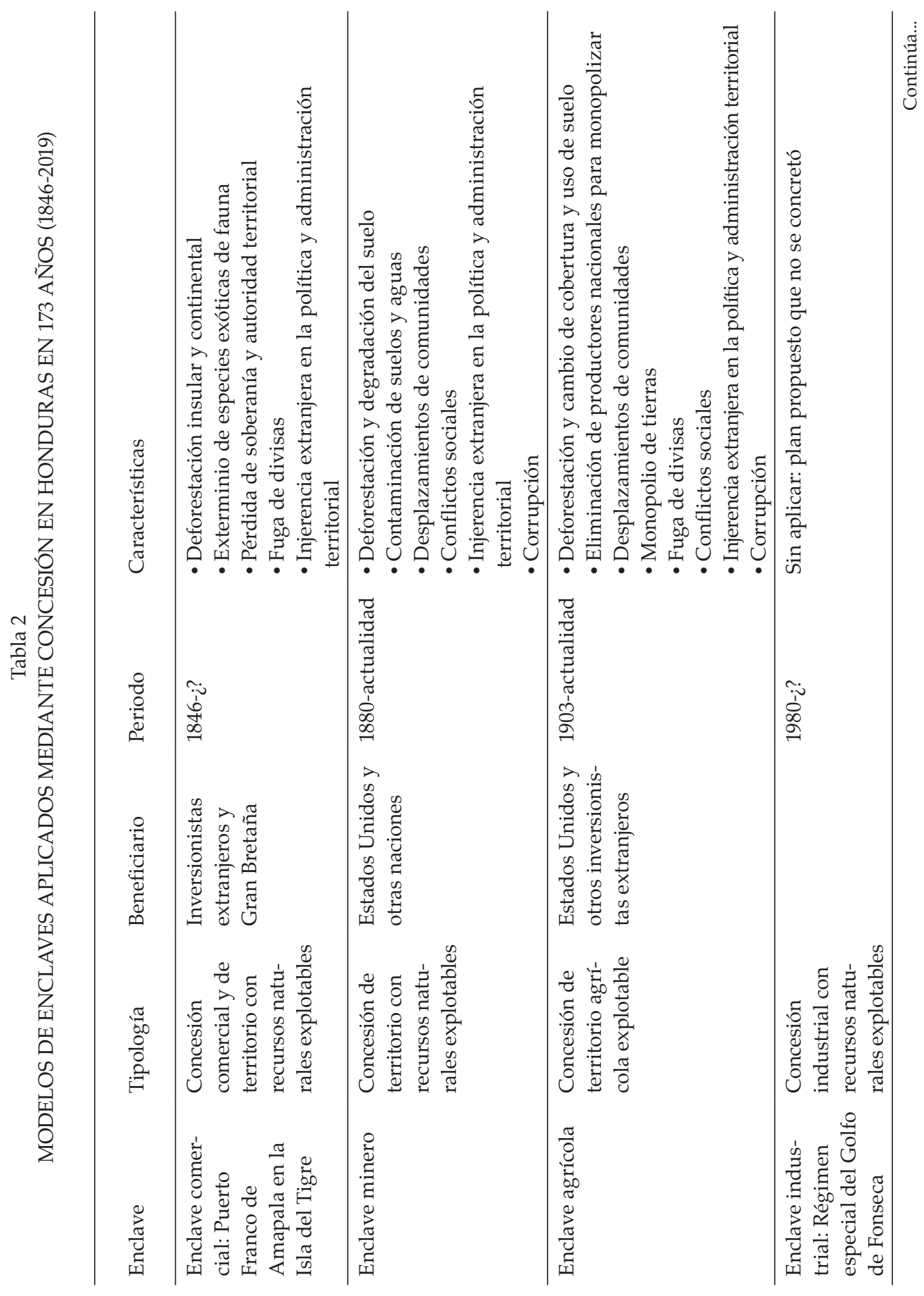




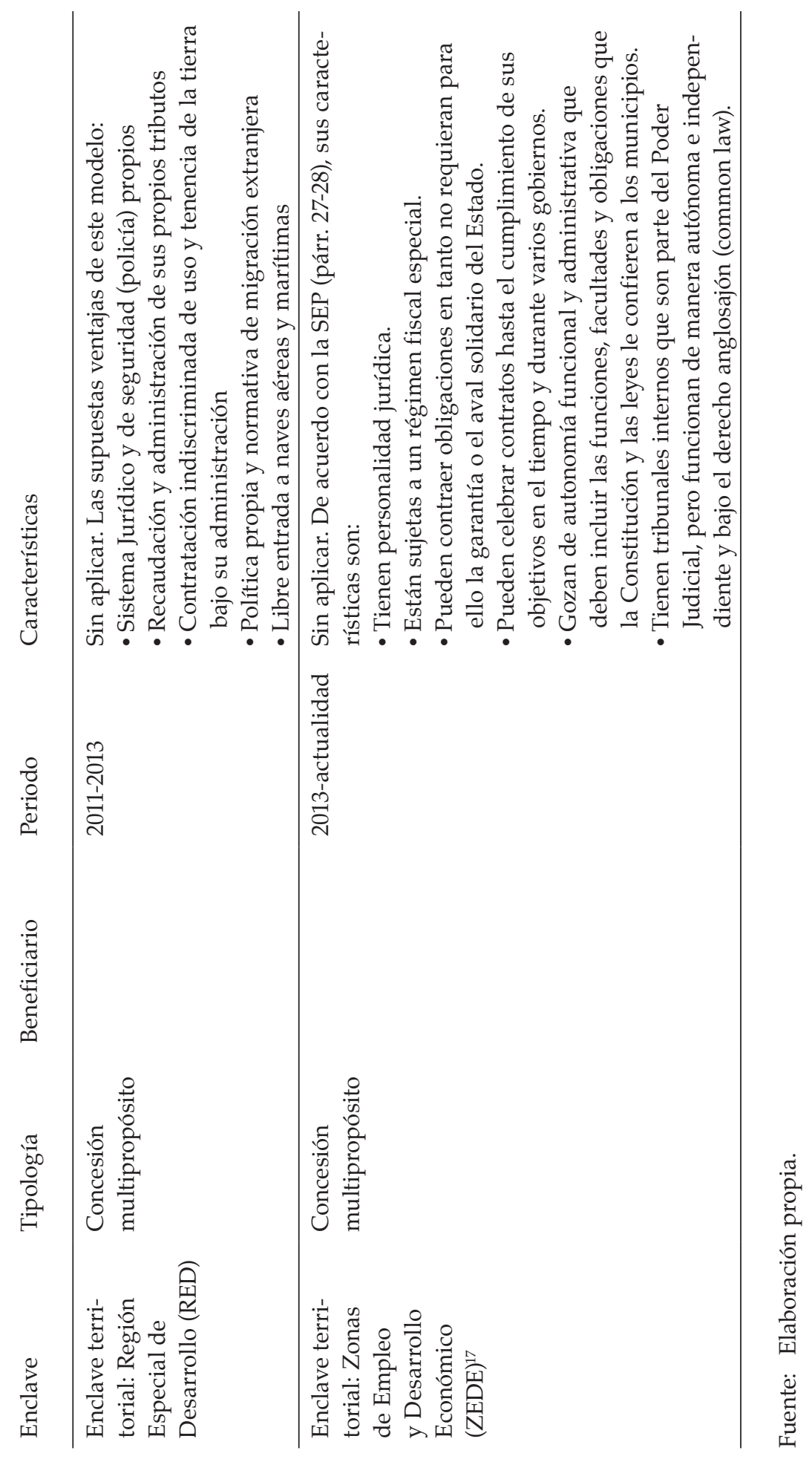


Se puede apreciar que la teoría original de las ciudades chárter está llena de buenas intenciones y con fundamentos teóricos basados en la experiencia de varias regiones para proporcionar una posible solución de desarrollo económico y social a naciones que carecen de estos. No obstante, tal y como lo expresó Paul Romer, el padre de la teoría de las ciudades chárter o ciudades modelo, con la aprobación en el 2014 de la creación de la primer RED, "el resultado fue un fracaso importante de transparencia" (Redacción, 2014). Lo anterior debido a que el gobierno de Honduras evita la conformación y la legalización de un comité de transparencia que evitara cualquier anomalía en el proceso de creación y administración de las ciudades chárter. Debido a esta razón, Paul Romer rechazó continuar con este proyecto en Honduras (Figura 13).

Tanto como Romer como las cuatro personalidades nunca asumieron sus cargos (como comité de transparencia), porque el gobierno no ordeno su publicación en el diario oficial La Gaceta. En cambio, el gobierno, a través de Coalianza y siendo testigo de honor el (entonces) presidente del Congreso Nacional, Juan Orlando Hernández, sí firma el pasado 3 de septiembre (del 2014) una carta de entendimiento con una empresa inexistente, de nombre MKG Groups, para desarrollar la primera "ciudad modelo" con una inversión inicial de 15 millones de dólares (Redacción, 2014).

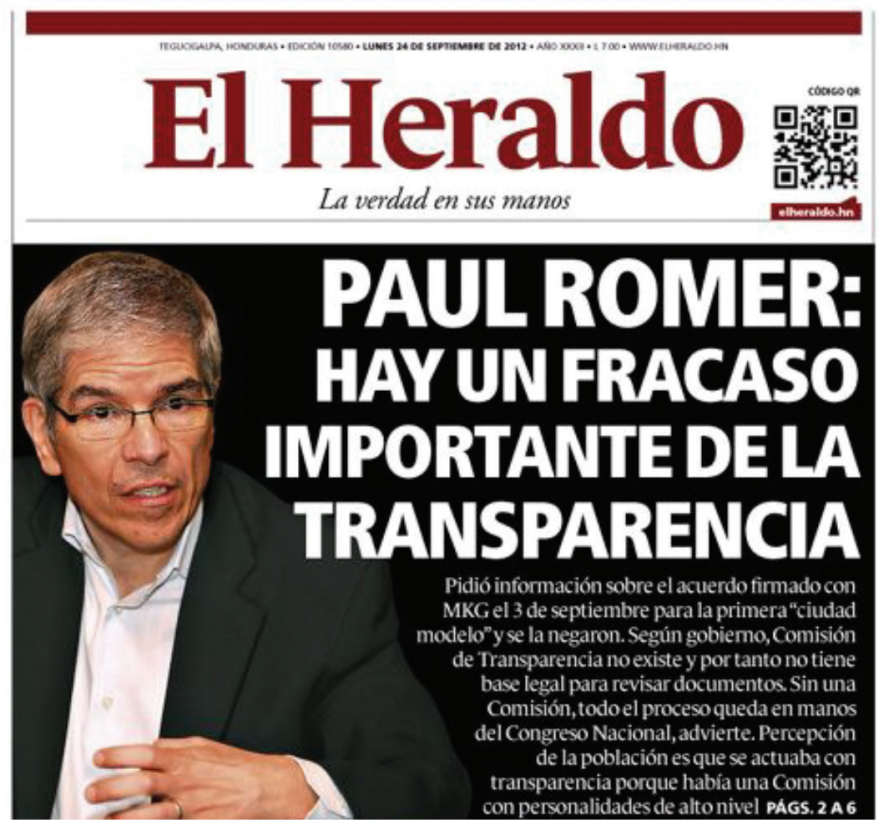

Fuente: Redacción, 2014. 


\section{Conclusiones}

La amplitud de opciones para concesionar el territorio nacional que nos muestran las ZEDE nos indican que veremos en este modelo fragmentador del territorio la aplicación de todos los modelos de enclaves mostrados en este documento. Lo anterior, por añadidura, deberá entenderse que en las ZEDE se revivirá cada una de las experiencias nefastas que se vivieron y se siguen viviendo con la aplicación de cada uno de los distintos enclaves que fallidamente se han aplicado en nuestro país y que demagógicamente se continúan presentando ante el pueblo como la panacea que sacará de su "subdesarrollo" a uno de los países más violentos, pobres y corruptos del mundo y que en la actualidad es mencionado como "Estado fallido"; esto debido a las caravanas migrantes que realizan un éxodo en masa hacia Estados Unidos de América, lo cual es todo lo contrario a lo que proponía Paul Romer, quien anhelaba impulsar la economía con el modelo de ciudades chárter o ciudades modelo.

Las lecciones aprendidas de los enclaves territoriales de los últimos dos siglos nos demuestran que las concesiones territoriales son instrumentos potenciales de pérdida de dominio del territorio a través de la figura legal de la concesión primero y luego mediante la compraventa de tierras. A la vez, está comprobado que los frutos económicos de los enclaves económicos no se transfieren al país anfitrión, sino hacia la economía de origen del inversionista invitado. Quizás el único ingreso directo que ofrecen este tipo de concesiones es el pago de tributos por sus actividades económicas; sin embargo, como lo muestran las concesiones mineras actuales, este tipo de aportes monetarios a la economía nacional son sorprendentemente bajos en comparación a las ganancias exportadas masivamente al exterior.

La reducción de la pobreza en los municipios más pobres de Honduras no es prioridad en la política gubernamental de las ZEDE, por el contrario, una de sus prioridades es el concesionamiento del territorio para explotación de todos los recursos naturales del país. La sociedad hondureña también debe comprender el riesgo ambiental y social que conlleva la instalación de una ZEDE, esto significa prácticamente la privatización ilimitada de los recursos naturales nacionales, ya que en ningún documento oficial del gobierno establece un límite en la cantidad de territorio hondureño a concesionar.

$\mathrm{Al}$ analizar todos los enclaves que han existido en la época republicana de Honduras, desde 1846, existe una constante y es el hecho de que las concesiones de territorio han generado gobiernos paralelos en regiones del país donde el Estado hondureño no puede hacer prácticamente nada para evitar sucesos que no son provechosos para el país. Por ejemplo, en el caso de las concesiones bananeras, cuando fueron aplicadas en Honduras en el siglo pasado, los gobiernos de ese momento generaron un gobierno paralelo al cual no podían exigir cumplir la promesa de desarrollo, ya sea por incompetencia o corrupción, tal y como explica Del Cid: “Los gobiernos de aquel 
entonces eran demasiado débiles (y probablemente hasta faltos de patriotismo) como para exigir cumplimientos a empresas que se habían devenido excesivamente poderosas dentro del contexto nacional" (11).

Sobre el monitoreo de los resultados de esta política, manejar como único indicador "los empleos generados" para medir el impacto de la ZEDE es una de las grandes preocupaciones que debemos tener en lo referente a esta supuesta política de desarrollo, ya que la generación de 200000 empleos (tanto directos como indirectos, desde luego) es usado por la actual administración para justificar las ZEDE. No obstante, cuando la misma administración gubernamental informa que ha generado 912360 empleos, es decir, casi un millón, sin aplicar la política de las ZEDE (Presidencia 30-31), entonces, la pregunta que surge es: ¿por qué insistir en concesionar nuestro país si la actual administración ha quintuplicado ya la meta de las ZEDE?

Independientemente de la respuesta, gracias a esto queda clara la razón por la cual las ZEDE se renombraron como "Zonas de Empleo" en el 2017 (Presidencia 36). Paradójicamente el desarrollo económico dejó de ser la prioridad de las ZEDE para la actual administración gubernamental y ahora solo importa la cantidad de empleo a generar, tal y como sucedió con los enclaves bananeros, donde es más importante cuantificar unidades de personas empleadas que determinar si esto está trayendo verdadero desarrollo sostenible e inclusivo. A pesar de que el gobierno impulsor de las ZEDE indica que hasta el 2017 creó casi un millón de empleos, un año después vemos huir masivamente del país a centenares de hondureños en caravanas migrantes hacia el norte del continente, en busca de una "vida mejor", lo cual es lo que, paradójicamente, el gobierno está ofreciendo desde hace dos administraciones gubernamentales, pero que simplemente ha estado ofreciendo proyectos de escaso o nulo impacto como paliativo al déficit de vivienda, inaccesibilidad de servicios básicos y carencia de seguridad alimentaria.

Finalmente, debemos recordar que el propio autor del modelo de las ciudades chárter ha expresado que la aplicación de su modelo ha sido cambiada por un modelo carente de transparencia, es decir corrupto, al cual ha llamado "fracaso". Este fracaso reciente en la transparencia es lo que debemos tener claro en el tema de las RED, ZEDE o Zona de Empleo en Honduras. Así pues, sin importar la época, cuando se trata de política de concesiones o enclaves territoriales, nuestras autoridades gubernamentales han fracasado en esta una y otra vez, desde 1846 hasta la actualidad. Si buscamos la causa, podemos guiarnos por las palabras actuales de Romer y las antiguas de Wells, en especial en la obra de este último (de 1860), donde nos explica que el problema con los funcionarios públicos que administran a Honduras es que "les importa más su propio medro que la acuciosidad en el registro de las entradas del Estado" (Wells 503). Es por esta aseveración, que debemos preguntarnos, si después de dos siglos, esto ha cambiado. 


\section{Notas}

1 Desde el 2010, el partido nacional ha administrado por tres periodos presidenciales las políticas de desarrollo de Honduras. Por lo cual, la actual administración nacionalista goza hasta el momento de 12 años consecutivos en el poder (2010-2021).

Ephraim George Squier (1921-1888), se le considera el primer centroamericanista de los Estados Unidos y es reconocido como la persona que ideó y promovió la propuesta de proyecto del Ferrocarril Interoceánico de Honduras. Una de las características identificadas de este investigador es la crítica dura que realiza a los autores de mapas ingleses de Centroamérica en su época, ya que él mismo menciona que descubrió varios "servilismos" donde se cartografiaba las divisiones políticas de Centroamérica para beneficio de la corona inglesa. Entre los ejemplos que ofrecía Squier (1855), encontramos a la representación de Vera Paz como un Estado independiente en Guatemala, la cuadruplicación del territorio de Belice y un reino misquito ficticio que abarcaba casi una tercera parte del Istmo centroamericano.

En la época colonial esta actividad (minera) creció exponencialmente, a tal punto que Honduras fue el más importante distrito minero en Centroamérica en todo este periodo, ya que sus minas producían cuatro quintas partes $(80 \%)$ del mineral extraído por España en América Central (Thompson III).

De acuerdo con el diccionario digital de la Real Academia Española (RAE), la definición de Enclave es "Territorio incluido en otro con diferentes características políticas, administrativas, geográficas, etc.".

Según Selser, el 16 de octubre de 1849, el cónsul Chatfield desembarca con tropas inglesas del buque de guerra "Gorgon" donde se apoderan de la isla, arrían la bandera de Honduras e izan la bandera inglesa. Dos días después, 800 soldados ingleses ocupan la isla luego de desarmar a la población civil, que no era mucha. El 23 de octubre del mismo año, el gobierno de Nicaragua protesta por la ocupación violenta de esta isla a través de una nota oficial dirigida al cónsul Chatfield. De acuerdo con Durón, el Sr. Chatfield, cónsul de Gran Bretaña en Honduras, comunicó, a través de una nota al gobierno de Honduras, que el señor Carlos Dárdano Dota había sido nombrado Superintendente de la isla del Tigre y demás islas. A lo cual, el gobierno de Honduras respondió el 8 de noviembre de 1849 que no reconocía dicho nombramiento y no se hacía responsable de la seguridad de esta persona ni de sus intereses. Por su parte, el gobierno de El Salvador apoyó al hondureño, decretando el 4 de diciembre de ese mismo año su protesta y declarando ilegitima e injusta la ocupación de la isla del Tigre, por parte del Imperio británico.

“El estancamiento económico y la fragmentación política a escala nacional había impedido de modo decisivo, la formación de un sistema productivo más o menos dinámico... y la de un Estado nacional estable y consolidado. En consecuencia, la sociedad hondureña no tuvo en su propio seno una clase económicamente dominante capaz de responder en un momento determinado, a las nuevas demandas del mercado exterior y configurar así, un sistema productivo con una participación nacional significativa" (Murga Frassinetii 23).

Apoyándose en la Constitución de 1880, se crea el primer Código Minero en Honduras (aprobado en 1880 y entrado en vigor en 1881) para impulsar el concesionamiento de territorio a la explotación minera con capital extranjero (Palma-Herrera, 2017). durante la "Reforma Liberal", a través la constitución de 1880, él mismo también encontró 
apoyo en los principales diputados de ese momento, como Manuel Gamero, diputado por el Paraíso (presidente) y José Manuel Zelaya, diputado por Olancho (vicepresidente), tal y como se puede ver en la aprobación de dicha constitución.

"Cámara representativa de empresarios norteamericanos interesados en concesiones mineras en Honduras... actuaba como canal de comunicación recíproca entre el Estado Hondureño y los empresarios norteamericanos" (Molina-Chocano 70).

La segunda Ley General de Minería de Honduras se creó en este año para impulsar el rubro minero en el siglo XXI, previo a esta existió la primera Ley General de Minería de 1998.

¿Por qué Anchuria? Se estima que el autor utilizó un juego de palabras, ya que al no usar directamente el nombre "Honduras" (refiérase a hondo o alto), utiliza en contraposición el nombre de "Anchuria" (refiérase a anchura o ancho). Siendo ambos, dimensiones principales de figuras, entre otros.

Paul Romer nació en Denver, Colorado en los Estados Unidos. Estudió en la Universidad de Chicago, en el Instituto de Tecnología de Massachusetts y en la Universidad de Queen en Kingston, Ontario, Canadá. Recibió su doctorado en la Universidad de Chicago en 1983. Ha trabajado en la Universidad de Rochester, la Universidad de Chicago, la Universidad de California, Berkeley y la Universidad de Stanford. También se desempeñó como economista jefe en el Banco Mundial. Desde 2011 ha estado asociado con la Universidad de Nueva York (Nobel Prize).

El estatuto (Charter en inglés) de William Penn para Pennsylvania (que inspiró el término Charter City) fue un paso crítico en el desarrollo de reglas que imponen una separación entre la iglesia y el Estado. Su garantía legal de libertad de conciencia atrajo a personas de toda Europa. Tuvo una legitimidad instantánea para los inmigrantes en un momento en que la tolerancia religiosa en Europa y los Estados Unidos era extremadamente controvertida. En última instancia, este valor central de la creación social de Penn se extendió por todas las colonias y finalmente se incorporó a la Constitución de los Estados Unidos. De la misma manera, las reformas que tienen la oportunidad de afianzarse en las ciudades chárter pueden extenderse a la región circundante (Fuller y Romer).

14 Doctrina y regímenes políticos, desarrollados durante el siglo XX, en los cuales el Estado concentra todos los poderes en un partido único y controla coactivamente las relaciones sociales bajo una sola ideología oficial, de acuerdo con el diccionario de la RAE.

La administración presidencial 2014-2017 corresponden al abogado Juan Orlando Hernández, quien pasó de ser presidente del Congreso (2010-2013) a ser presidente de la República. Actualmente, logró continuar en la silla presidencial después de finalizado su periodo presidencial, mediante unas elecciones muy controversiales en el último año de su primer mandato. Importante es mencionar que, durante tres administraciones presidenciales, el abogado Juan Orlando Hernández es uno de los principales impulsores de la creación de las ciudades modelo. Su principal estrategia de gobierno es centralizar los tres poderes del estado, fuerzas armadas y las transferencias municipales (parte del presupuesto de la Republica destinado al funcionamiento de los gobiernos municipales) a un solo poder decisión, el presidencial.

16 De acuerdo con un informe de Global Witness, en el año 2017 se definió a Honduras como el país más peligroso para las personas activistas protectoras del medioambiente. 
A partir del 2017, las Zonas Especiales de Desarrollo y Empleo (ZEDE) se les renombró como Zonas de Empleo (Zede), pero sin ningún fundamento legal o técnico para esto. Por lo cual, a pesar del cambio de nombre, técnica y legalmente, siguen siendo el mismo modelo creado en el 2013, ya que no se ha derogado todavía la figura legal de Zona Especial de Desarrollo y Empleo, ni mucho menos sustituida por las Zonas de Empleo.

\section{Bibliografía}

Asamblea Nacional Constituyente de Honduras. Constitución de la República de Honduras de 1880. Recuperado de http://www.cervantesvirtual.com/obra-visor/constitucion-de-honduras-de-1880/html/44ec3699-d923-4453-8da4-3f3ab7f0fe36_2.html\#I_9

Congreso Nacional de Honduras. Constitución de la República de Honduras de 1982. Recuperado de pdba.georgetown.edu/Parties/Honduras/Leyes/constitucion.pdf

Congreso Nacional de Honduras. Ley orgánica de las zonas de empleo y desarrollo económico (ZEDE). Tegucigalpa: Empresa Nacional de Artes Gráficas, 2013. Impreso.

Davidson, Adam. Who Wants to Buy Honduras? New York Times. It's the Economy. Recuperado de https://www.nytimes.com/2012/05/13/magazine/who-wants-to-buy-honduras. html

Del Cid, J. Rafael. Economía bananera y desarrollo nacional. Tegucigalpa: Sistema bibliotecario de la UNAH, 1984.

Durón, Rómulo E. Efemérides de Honduras: año 1849. Tegucigalpa: Revista del Archivo y Biblioteca Nacional, 1849. Instituto Hondureño de Antropología e Historia.

Equipo Nikzor. Honduras. La Defensa de los Derechos Humano: una Actividad de Alto Riesgo. Recuperado de http://www.derechos.org/nizkor/honduras/doc/pbi.html

FOSDEH. Mapa de pobreza por método INE, 2001. Recuperado de https://mapasfosdeh.files.wordpress.com/2011/09/24-mapa-de-pobreza-por-mc3a9todo-ine.jpg

Fuller, Brandon y Romer, Paul. Success and the city: how charter cities could transform the developing world. Macdonald-Laurier Institute. Recuperado de https://www.macdonaldlaurier.ca/files/pdf/How-charter-cities-could-transform-the-developing-worldApril-2012.pdf

Ministerio de Cultura, Turismo e Información. La nueva política bananera de Honduras: el fin del sistema concesionario de las compañías bananeras norteamericanas. Tegucigalpa: Ministerio de Cultura, Turismo e Información, 1975.

Molina-Chocano, Guillermo. Estado liberal y desarrollo capitalista en Honduras. Tegucigalpa: Banco Central de Honduras, 1976.

Mulligan, José. El dueño único de Dole. ALAI. América Latina en Movimiento. Recuperado de https://www.alainet.org/es/active/15473

Murga Frassinetti, Antonio. Enclaves y sociedad en Honduras. Tegucigalpa: Departamento Editorial de la Universidad Nacional Autónoma de Honduras, 1978.

Nobel Prize. Paul M. Romer - Facts - 2018. NobelPrize.org. Nobel Media AB 2019. Recuperado de https://www.nobelprize.org/prizes/economic-sciences/2018/romer/facts/

OXFAM. Territorios en riesgo: minería, tierra y agua en Honduras. OXFAM. Recuperado de www.academia.edu/35213571/Territorios_en_riesgo_Mineria_tierra_y_agua_en_ Honduras_2017 
Palma-Herrera, José Luis. Modelo de catastro minero en Honduras. Revista Geografía y Sistemas de Información Geográfica, 9, 9(2017): 51-71. Recuperado de https://revistageosig.wixsite. com/geosig/geosig-9-2017

Palma-Herrera, José Luis. Impulsando la paz y la protección del ambiente en el país más peligroso del mundo: estudio geográfico para evitar el impacto negativo de la minería en Honduras. Geografías al servicio de los procesos de paz. La Paz, Bolivia: Instituto de Investigaciones Geográficas, 2018.

Presidencia de Honduras. Informe 4 años de logros. Presidencia de la República. Recuperado de presidencia.gob.hn/PRESIDENCIAL/virtual/Informe/

Price, Douglas, Seiichi Nakamura, Shintaro Suzuki, James Burton y Vera Tiesler. New isotope data on Maya mobility and enclaves at Classic Copan, Honduras. Journal of Anthropological Archaeology. Recuperado de https://www.sciencedirect.com/science/ article/pii/S0278416514000154

Real Academia Española. Diccionario de la lengua española. Recuperado de https://dle.rae. es/?w=diccionario

Redacción. (23 de octubre de 2017). 200 mil empleos busca generar el gobierno por medio de las ZEDE. El Heraldo. de www.elheraldo.hn/pais/1119201-466/200-mil-empleos-buscagenerar-el-gobierno-por-medio-de-las-zede

Redacción. (14 de agosto de 2017). Coreanos presentan diseño y estudio del puerto de Amapala. El Heraldo. Recuperado de https://www.elheraldo.hn/pais/1098827-466/ coreanos-presentan-dise\%C3\%B1o-y-estudio-del-puerto-de-amapala

Redacción. (7 de abril de 2014. Romer: Han desviado las normas de transparencia en ciudades modelo. El Heraldo. Recuperado de www.elheraldo.hn/alfrente/565447-209/romerhan-desviado-las-normas-de-transparencia-en-ciudades-modelo

Romer, Paul. A new city in Honduras. Paul Romer. Recuperado de paulromer.net/a-new-cityin-honduras/

Sánchez, J. Breve historia y antecedentes de Standard Fruit de Honduras, S.A. La Ceiba: C\&M Copias y Más, 1994.

Secretaria de Comunicaciones, Obras Públicas y Transporte. Informe de la investigación y memorias del estudio pre-inversional Isla del Tigre (Amapala). Tegucigalpa: Dirección General de Urbanismo, 1980.

Secretaria de Estado de la Presidencia. Honduras se declara listo para implementar las Zonas de Empleo. Recuperado de http://www.sep.gob.hn/sitio/historial-de-noticias/gobierno/ honduras-se-declara-listo-para-implementar-las-zonas-de-empleo

Selser, Gregorio. Cronología de las intervenciones extranjeras en América Latina. Tomo II, 1849-1898. México: Centro de Investigaciones Interdisciplinarias en Ciencia y Humanidades, UNAM, 1997.

Slutzky, Daniel y Alonso, Esther. Empresas transnacionales y agricultura: el caso del enclave bananero en Honduras. Tegucigalpa: Editorial Universitaria, 1980.

Squier, Ephraim G. Apuntamientos sobre Centro América, Honduras y El Salvador: su geografía, topografía, clima, población, riqueza, producciones, etc., etc. Y el propuesto Ferrocarril de Honduras. Trad. León Alvarado. Managua: PDVSA, 2004. Biblioteca Enrique Bolaños. Recuperado de www.enriquebolanos.org/media/archivo/CCBA-SERIE\%20 VIAJEROS-05-Apuntamientos\%20sobre\%20Centroamerica-Honduras $\% 20 \mathrm{y} \% 20 \mathrm{El} \% 20$ Salvador-Parte1de4.pdf 
Thompson III, Noble Richard. The economic geography of the mining industry of Honduras, Central America. Tennessee: The University of Tennessee, 1973.

Vogeler, Ingolf. Central American Bananas. University of Wisconsin-Eau Claire. Recuperado de https://people.uwec.edu/ivogeler/w111/banana.htm

Wells, William V. Exploraciones y aventuras en Honduras. Trad. Pio Suarez Romero. Tegucigalpa: Banco Central de Honduras, 1960. Biblioteca virtual Miguel de Cervantes. Recuperado de http://www.cervantesvirtual.com/obra/exploraciones-y-aventuras-en-honduras/

José Luis Palma-Herrera. Hondureño. Máster en Ordenamiento y Gestión del Territorio. Especialista e investigador académico voluntario del Grupo de Investigación "Movilidad y Desarrollo Urbano Sostenible (MODUS)" de la Dirección de Investigación Científica Universitaria (DICU) de la Universidad Nacional Autónoma de Honduras (UNAH) y consultor investigador para ACNUR Honduras, GOAL Honduras y la Asociación de Municipios de Honduras (AMHON).

Contacto: jose.palma@unah.edu.hn

ORCID: 0000-0002-3578-2714 